Illinois State University

ISU ReD: Research and eData

Theses and Dissertations

5-3-2016

Elementary General Education Teachers' Perspectives Towards the Inclusion of Students with Emotional Disturbances

Leona E. O'Dear

Illinois State University, odearle@yahoo.com

Follow this and additional works at: https://ir.library.illinoisstate.edu/etd

Part of the Special Education Administration Commons, and the Special Education and Teaching Commons

Recommended Citation

O'Dear, Leona E., "Elementary General Education Teachers' Perspectives Towards the Inclusion of Students with Emotional Disturbances" (2016). Theses and Dissertations. 590.

https://ir.library.illinoisstate.edu/etd/590

This Thesis is brought to you for free and open access by ISU ReD: Research and eData. It has been accepted for inclusion in Theses and Dissertations by an authorized administrator of ISU ReD: Research and eData. For more information, please contact ISUReD@ilstu.edu. 


\title{
ELEMENTARY GENERAL EDUCATION TEACHERS' PERSPECTIVES TOWARDS THE INCLUSION OF STUDENTS WITH EMOTIONAL DISTURBANCES
}

\author{
Leona O'Dear
}

\section{Pages}

The inclusion of students with emotional disturbances (ED) in the least restrictive environment has been encouraged nationally through litigation and legislation. Despite this fact, $38.1 \%$ of the students with ED spend less than $40 \%$ of their day in a regular education classroom due to several barriers (U.S. Department of Education, 2014). Research has demonstrated that one of the barriers to inclusion is general education teachers' attitudes towards the inclusion of students with disabilities (Andreasen, 2014a; MacFarlane \& Woolfson, 2013; Ross-Hill, 2007; Tsokova \& Tarr, 2012). The purpose of this research study was to use a qualitative design to study the perspectives of general education teachers at the elementary level in an urban Illinois school district towards the phenomenon of the inclusion of students with ED. Five participants were interviewed to provide data for the study.

The findings of this research study show that there are mixed perspectives among elementary, general education teachers towards the inclusion of students with ED. 
Participants feel that it made them a stronger teacher and benefited students with ED through social modeling. They were concerned, however, about the work environment and safety for others. Participants felt there were four main barriers to the inclusion of students with ED: (a) safety, (b) student behaviors, (c) time, and (d) information. However, these barriers could be addressed through providing the supports of planning, professional development and training, and staff. From the review of literature and these findings, I developed a list of recommendations for policies and practice and implications for further study.

KEYWORDS: Elementary, General Education Teacher Perspectives, Emotional Disturbances, Inclusion 
ELEMENTARY GENERAL EDUCATION TEACHERS' PERSPECTIVES TOWARDS THE INCLUSION OF STUDENTS WITH EMOTIONAL

DISTURBANCES

LEONA O'DEAR

A Thesis Submitted in Partial Fulfillment of the Requirements for the Degree of

MASTER OF SCIENCE

Department of Special Education

ILLINOIS STATE UNIVERSITY

2016 
Copyright 2016 Leona O’Dear 


\section{ELEMENTARY GENERAL EDUCATION TEACHERS' PERSPECTIVES TOWARDS THE INCLUSION OF STUDENTS WITH EMOTIONAL DISTURBANCES}

LEONA O’DEAR

COMMITTEE MEMBERS:

Mark Zablocki, Chair

Yojanna Cuenca-Carlino

Stacey E. Hardin 


\section{ACKNOWLEDGMENTS}

I have often heard the saying that it takes a village to raise a child. I did not realize that it would also take a village to finish my thesis. I could not have accomplished it without the assistance of many individuals. I am forever indebted to the support that I received throughout my many years of education.

My mother, Anita Munden, has been my hero for a long time now. Watching her pursue further education showed me that I should never stop reaching for my dreams. Knowing how hard she worked modeled for me the persistence and dedication that it would take.

My husband, Joshua O’Dear, and my children, Rylee and Sean, have supported me throughout my master's program. They have tolerated the long nights of studying and the nights that I was gone for class. I could not have done this without the support they provided me.

My advisor, my chair, and my guide, Dr. Mark Zablocki, has inspired me with his knowledge of students with emotional disturbances. The research that he shared with me has only increased my passion for working with these students. My committee members, Dr. Yojanna Cuenca-Carlino, and Dr. Stacey Hardin, provided me with valuable guidance for directions to take my research. 
My peer reviewer and one of my editors, Nathan Stewart, helped in guiding my writing along the way. His knowledge of qualitative research was precious. I appreciate all the time he spent reviewing my work and editing my papers.

My co-worker and the second of my editors, Risé Davis, has been an invaluable support during my time working on my thesis. From listening to my tangents about the inclusion of students with emotional disabilities to correcting my grammar, I could not have asked for a better co-worker and friend.

My village was a strong support network that I leaned on several times during the completion of my thesis. Without them, I would not have made it. With them, I can reach the stars.

L. O. 


\section{CONTENTS}

Page

ACKNOWLEDGMENTS

CONTENTS

iii

TABLES

vi

\section{CHAPTER}

I. INTRODUCTION 1

Background of the Study 1

Research Problem $\quad 9$

Research Questions 10

Definition of Terms 10

Emotional Disturbances (ED) 10

General Education Elementary Teacher $\quad 11$

Inclusion $\quad 11$

Least Restrictive Environment 11

$\begin{array}{ll}\text { Perspectives } & 12\end{array}$

$\begin{array}{ll}\text { Social Modeling } & 12\end{array}$

$\begin{array}{ll}\text { Significance of the Study } & 12\end{array}$

$\begin{array}{ll}\text { Theoretical Framework } & 12\end{array}$

$\begin{array}{ll}\text { Statement of Position } & 13\end{array}$

II. LITERATURE REVIEW 15

Introduction $\quad 15$

Perspectives on the Inclusion of Students with Disabilities 16

Teacher Perspectives 16

Administrator Perspectives 18 
Perspectives on the Inclusion of Students with Emotional Disturbances (ED)

Impact of Inclusion

Students with Disabilities

Students without Disabilities

Overall Barriers to Inclusion

Overall Supports to Inclusion

Summary

III. METHODS

Research Design

Instrument

Research Setting

Participants

Procedures

Data Analysis

Ethical Issues

IV. RESULTS

Introduction

Emergent Themes

Perspectives

Positive perspectives

Negative perspectives

Barriers

Safety

Student behaviors

Time

Information

Planning for crisis $\quad 50$

Professional development and training 51

Staff $\quad 52$

Summary 
$\begin{array}{ll}\text { Overview } & 57\end{array}$

Emergent Themes and Research 58

$\begin{array}{ll}\text { Perspectives } & 58\end{array}$

Barriers $\quad 59$

$\begin{array}{ll}\text { Supports } & 60\end{array}$

$\begin{array}{ll}\text { Limitations of the Study } & 61\end{array}$

Personal Bias $\quad 62$

Generalizability $\quad 62$

Interview Process $\quad 63$

Personal Connections $\quad 63$

Researcher Bias 64

Recommendations for Policies and Practice 64

$\begin{array}{ll}\text { Barriers } & 65\end{array}$

Perspectives 65

Information sharing $\quad 65$

$\begin{array}{ll}\text { Supports } & 66\end{array}$

Planning for crisis $\quad 66$

Professional development $\quad 67$

$\begin{array}{ll}\text { Staff } & 67\end{array}$

Implications for Further Study $\quad 68$

Concluding Remarks 69

$\begin{array}{ll}\text { REFERENCES } & 71\end{array}$

APPENDIX A: Recruitment Flyer $\quad 76$

APPENDIX B: Semi-Structured Interview Protocol 77 


\section{TABLES}

Table $\quad$ Page

1. Interview Questions 35

2. Demographics of Participants 37 


\section{CHAPTER I}

\section{INTRODUCTION}

\section{Background of the Study}

The inclusion of students with disabilities has been encouraged internationally, through legislation and policies, for over 20 years (MacFarlane \& Woolfson, 2013; Tsokova \& Tarr, 2012). Article 26 of the United Nation's Universal Declaration of Human Rights states that the full participation of all students in education is a human right (Jones, Fauske, \& Carr, 2011). Additionally, Article 24 of the United Nations Convention on the Rights of Handicapped People calls for the education of all students to be inclusive (Khudorenko, 2011).

In the United States, the philosophical roots for inclusive education can be found in the struggle for civil rights and in court decisions such as Brown v. Board of Education (1954) (Hoffman, 2006; Jones, Fauske, \& Carr, 2011). In 1954, Brown v. Board of Education established the principle that school segregation denies students an equal opportunity at education. The ruling from Brown v. Board of Education found that segregation of students in public schools violated the Fourteenth Amendment's Equal Protection Clause. This case became the basis for other lawsuits that dealt with discrimination against people who belong to various groups. In the opinion delivered by Chief Justice Warren, attention was called to the psychological feeling of inferiority that segregation caused (Blankenship, Boon, \& Foore, 2007). Through Brown v. Board of 
Education and the civil rights movement, the concept of "separate but equal" was not actually equal or acceptable in the eyes of the law, whether it is in the school or in other settings.

During the 1940s, 1950s, and 1960s, a civil rights debate formed over whether segregation or integration was best for students with disabilities. The push for integration gained strength from parents and practitioners who questioned the effectiveness and ethics of segregated settings (Osgood, 2005). This debate was even the topic of the 1945 annual meeting for the International Council for Exceptional Children, where a panel discussed "Segregation versus Non-Segregation of Exceptional Children" (Osgood, 2005, p. 44). In 1953, John Tenny published "The Minority Status of the Handicapped" in Exceptional Children and called attention to the similarities between the segregation of students with disabilities and the segregation of minorities. In 1958, Congress passed PL85-905, which provided loan services to create closed caption films, and PL85-926, which created federal support for the schooling of teachers for children with intellectual disabilities (Osgood, 2005). These laws were supported through advocacy from professional advocacy groups such as the International Council for Exceptional Children. The year 1958 also saw the development of a workshop for teachers that had the goal of improving the attitudes of educators towards students with disabilities. During this time, the changes for their civil rights in the lives of individuals with disabilities were not just brought on by Congress.

In the 1960s, parental activism led to an expansion of special education offered within the public schools setting and an expansion of programs outside of the education setting (Dudley-Marling \& Burns, 2014). In 1968, the Special Olympics had their first 
International Special Olympics Summer Games and offered an opportunity for students with intellectual disabilities to participate in a major sporting event (Special Olympics, 2015). Also during the late 1960 s, there was a move from an institution- to communitybased setting for the care, treatment, and education of people with disabilities (Osgood, 2005). In the 1960s and 1970s, there was an expansion of advocacy groups for people with disabilities, such as the National Association for Retarded Children (NARC), the National Down Syndrome Congress, and the National Council on Disability (NCD) (Osgood, 2005).

In the early 1970s, court cases specifically focusing on the rights of children with disabilities began to gain momentum. Between 1971 and 1975, more than forty-six court cases that addressed the segregation of students with disabilities were decided in twentyeight of the states (Osgood, 2005). Four of these court cases, Pennsylvania Association for Retarded Children (PARC) v. Commonwealth of Pennsylvania (1971), Mills v. Board of Education of the District of Columbia (1972), Diana v. State Board of Education (1970), and Larry P. v. Riles (1972), were considered the most influential in the push for students with disabilities being educated in a setting closest to their normally developing peers (Osgood, 2005). In PARC v. Commonwealth of Pennsylvania (1971) and Mills v. Board of Education of the District of Columbia (1972) the rulings "challenged the practice of excluding disabled children from public schools" (Osgood, 2005, 104-105). Both of these cases found that the public schools had to provide all children with a free and appropriate education. In Mills v. Board of Education (1972), the call for a free and appropriate education was extended to all students with disabilities (Blankenship, Boone, $\&$ Fore, 2007). In this case, two of the students had behavioral problems and the courts 
found that these students had the right to a free and appropriate education, too (Mills $v$. Board of Education, 1972). In Diana v. State Board of Education (1970) and Larry P. v. Riles (1972), the courts charged schools to address the concern of cultural bias in the identification process due to the overrepresentation of racial minorities in special education. These court decisions began creating change in schools.

During this time frame, changes were also happening in legislation. In 1973, the civil rights of individuals with disabilities became protected under Section 504 of the Vocational Rehabilitation Act of 1973 (Osgood, 2005). Section 504 protected individuals with disabilities from discrimination under any program or activity receiving Federal funds, which includes schools. The Vocational Rehabilitation Act of 1973 led to the Americans with Disabilities Act (ADA) of 1990. Both were in support of the civil rights of individuals with disabilities. Legislation was also making drastic changes for the educational rights of students with disabilities. In 1975, the Education for All Handicapped Children Act was passed (Dudley-Marling \& Burns, 2014). This act required schools that received federal funds to provide equal access to education for children with disabilities. In 1990, the Education for All Handicapped Children Act was renamed the Individuals with Disabilities Education Act (IDEA) (Blankenship, Boone, \& Fore, 2007). IDEA mandates that students with disabilities be educated with students without disabilities to the maximum extent appropriate. IDEA also puts the financial burden for a student's education on the school district. Legislatively, the requirement for the least restrictive environment was being reinforced.

Throughout the 80 's and 90 's, while change was occurring legislatively, changes continued to occur in the courtrooms as well. Through court cases such as Daniel R. R. v. 
State Board of Education (1989) and Sacramento City Unified School District v. Holland (1992), the courts made decisions that provided criteria for school districts to determine what placement is appropriate for students with disabilities (Nelson, 2000). These criteria that must be considered included "(a) academic benefit, (b) social benefit, (c) cost of providing special education services in general education, and (d) disruption or impact a student with special needs may have on a general education class" (Nelson, 2000, p. 20). In Daniel R. R., the courts placed limits on the accommodations that school districts had to provide in the general education setting and provided guidelines that should be reviewed when deciding to place a student in a more restrictive setting. With the accommodations, the court ruled that the regular education teacher could not be expected to focus all or most of the teacher's time on the student with disabilities. They also stated that the regular education program must still be recognizable even with accommodations and modifications. For the guidelines, the courts asked two questions. First, had the school district "proved that the child could not be educated in a regular classroom using supplementary aids and support services" (Nelson, 2000, p. 18)? Second, was the student with disabilities participating with normally developing peers? With these court cases, and others that have followed, special education changed as a result of "legislative action, court decisions, practical experience, and exposure to some long-held but never outdated visions as well as concerns" (Osgood, 2005, p. 180).

Over time, with influence from court cases and state and federal law, the move in education developed into an increasing push for inclusion. For the purpose of this research study, inclusion is viewed as the "commitment to educate each student, to the maximum extent appropriate, in the school and classroom the student would attend" 
(Hoffman, 2006, p. 15). In this form of inclusion, support services are provided to the student in the general education classroom to the maximum extent possible. Since the passing of IDEA, Congress has begun giving annual reports on the implementation of IDEA. According to the $36^{\text {th }}$ Annual Report to Congress on the Implementation of the Individuals with Disabilities Education Act, 2014, students with disabilities placed partially within a regular classroom setting have increased from $39.8 \%$ in 1992 to $61.5 \%$ in 2014 (U.S. Department of Education, 1995; U.S. Department of Education, 2014). This means that, $19 \%$ of students with disabilities are educated in a setting that is less than $40 \%$ of their school day in a regular education setting (U.S. Department of Education, 2014). These numbers tell us that more students are being included in a regular education setting than not.

Not all students with disabilities have a high percentage of inclusion within the regular education setting. For some students, it is more common to be in a more restrictive setting. For professionals who serve students with emotional disturbances (ED), one of the problems faced is a pattern of placement in more restrictive educational settings (Landrum, Katsiyannis, \& Archwamety, 2004). According to the 36th Annual Report, $38.1 \%$ of the students with ED spend less than $40 \%$ of their day in a regular education classroom. Being in a more restrictive setting is even more common for students with ED in Illinois. In Illinois, $47.8 \%$ of students with ED spend less than $40 \%$ of their day in a regular education classroom (U.S. Department of Education, 2014).

The tendency for students with ED to be educated in the more restrictive environments is concerning because it impacts their long-term success in school. Landrum, Katsiyannis, and Archwamety (2004) analyzed data from the U.S. Department 
of Education to look for trends in placements and school exit patterns for students with ED. Their findings were similar to those that are reported in the $36^{\text {th }}$ Annual Report to Congress on the Implementation of the Individuals with Disabilities Education Act (2014). The first trend that they analyzed was that there was an overall increasing trend to serve students with disabilities with less intensive special education services (Landrum et al., 2004). There was a second trend of the more restrictive placement pattern existing for students with ED (Landrum et al., 2004). The concerning part is that Landrum et al. also identified a relationship between placement and school exit. This relationship showed that students with ED who were placed in more restrictive settings were more likely to drop out than students with ED who were placed in general education classrooms (Landrum et al., 2004). The more restrictive the placement, the more likely that the student would not graduate with a diploma.

It is concerning that there has been little change in placement for students with ED between the Landrum report and the $36^{\text {th }}$ annual report. The knowledge that more restrictive placements lead to students with ED being more likely to drop out should only further the call for providing a less restrictive setting, but there are barriers that interfere with a placement within a general education classroom. Landrum et al. mention that one explanation for the more restrictive placements could be due to the need for students with ED to have intensive behavioral and instructional challenges. Other research states that the inclusion of students with ED is particularly difficult for teachers due to behavioral outbursts that interrupt the learning environment and the difficulty students with ED have in building and maintaining interpersonal relationships with peers and adults (MacFarlane \& Woolfson, 2013). Part of this is because the needs of students with ED are beyond the 
range of what regular education teachers have been prepared to work with (Reasons, 2005).

For students with ED, the barriers to inclusion need to be addressed and overcome to increase the amount of students with ED who are included in their regular education environment. Based on the narratives from multiple individuals in their book, Tsokova and Tarr (2012) report the fact that the barriers to the inclusion of students with disabilities can arise on a communicative, attitudinal, physical, and organizational standpoint. These barriers can take the form of lack of knowledge about disabilities, lack of administrative support, and lack of support from other staff members (Fuchs, 2010; Orr, 2009). Other researchers have reported that the perspectives of administrators and general education teachers are one of the barriers to the successful inclusion of students with disabilities (Andreasen, 2014a; MacFarlane \& Woolfson, 2013).

The fact that these barriers exist, especially those of the general education teachers' perspectives, is concerning for multiple reasons. First, inclusion is a civil right. The Vocational Rehabilitation Act of 1973 and the $A D A$ protects individuals with disabilities from discrimination. Brown v. Board of Education (1954) demonstrated that separate schooling was not equal and was discrimination. Thus, when students with disabilities are not provided education in the least restrictive environment, they are being discriminated against and their civil rights are being violated. Second, inclusion is also an educational right. Congress, through the passage of laws such as $I D E A$, and the court system, through cases such as Mills v. Board of Education (1972), have shown that the burden lies on the school to provide the least restrictive environment possible based on the students' needs for all students with disabilities, including those with behavioral 
problems. Third, research has demonstrated a negative relationship between graduation with a diploma and placement within a more restrictive setting (Landrum et al., 2004). Fourth, research has demonstrated that there is a direct relationship between the teachers' attitudes and the success of the students with disabilities within an inclusive setting (Ross-Hill, 2007). Research has also stated that the beliefs that teachers hold about inclusion influence their ability to feel successful working with students with disabilities (Fuchs, 2010). In order to provide this least restrictive environment successfully, the barriers that exist must be addressed. Before these barriers can be addressed, they must be examined carefully so that their nature can be understood.

\section{Research Problem}

In the United States, legislation and court cases over the past fifty years have been pushing towards an inclusive educational setting (Blankenship, Boone, \& Fore, 2007; Osgood, 2005). The decisions from court cases like Mills v. Board of Education find that all students with disabilities have the right to be included in the regular education classroom (Blankenship, Boone, \& Fore, 2007). Despite the push for inclusion, in Illinois, $47.8 \%$ of students with ED spend less than $40 \%$ of their day in a regular education setting (U.S. Department of Education, 2014). Past studies have demonstrated that one of the barriers to inclusion exists in general education teachers' attitudes towards the inclusion of students with disabilities (Andreasen, 2014a; MacFarlane \& Woolfson, 2013; Tsokova \& Tarr, 2012). These studies also call for further investigation of this barrier in order to address the perspectives that exist. There is a gap in current information related to the elementary, general education teachers' perspectives towards 
the inclusion of students with ED within the United States. The majority of studies that have been completed in this area have applied quantitative methodological approaches.

The specific problem I intend to investigate is the perspectives of general education, elementary teachers towards inclusion of students with ED within an urban Illinois school district. According to Ross-Hill (2007), there is a direct relationship between the teachers' attitudes and the success of the student within the inclusive classroom. There is a research gap that exists as to what the perspectives of general education, elementary school teachers are towards the inclusion of students with ED within the general education, elementary setting. The purpose of this research study was to use a qualitative design to study the perspectives of general education teachers at the elementary level in an urban Illinois school district towards the phenomenon of the inclusion of students with ED.

\section{Research Questions}

1. What are the perspectives of general education teachers at the elementary level towards the inclusion of students with emotional disturbances?

2. What do general education teachers at the elementary level perceive as barriers to the inclusion of students with emotional disturbances?

3. What do general education teachers at the elementary level perceive as supports that are needed to assist the inclusion of students with emotional disturbances?

\section{Definition of Terms}

\section{Emotional Disturbances (ED)}

An emotional disturbance means a condition exhibiting one or more of the following characteristics over a long period of time and to a marked degree that adversely 
affects a child's educational performance: (a) an inability to learn that cannot be explained by intellectual, sensory, or health factors; (b) an inability to build or maintain satisfactory interpersonal relationships with peers and teachers; (c) inappropriate types of behavior or feelings under normal circumstances; (d) a general pervasive mood of unhappiness or depression; (e) a tendency to develop physical symptoms or fears associated with personal or school problems. The term emotional disturbance includes schizophrenia.

\section{General Education Elementary Teacher}

A teacher who is certified within the state of Illinois to teach general education courses at the elementary (K-6) level.

\section{Inclusion}

Providing special education services to a student with disabilities within the general education classroom in the school they would attend if not disabled. Educating students with disabilities with their peers without disabilities.

\section{Least Restrictive Environment}

To the maximum extent appropriate, school districts must educate students with disabilities in the regular classroom with appropriate aids and supports, referred to as "supplementary aids and services," along with their nondisabled peers in the school they would attend if not disabled. 


\section{Perspectives}

The views, feelings, opinions, and reflections of the person being interviewed.

\section{Social Modeling}

Learning to imitate others by observing their behavior.

\section{Significance of the Study}

In Illinois, $47.8 \%$ of students with ED spend less than $40 \%$ of their day in a regular education classroom. Almost half of students with ED are not being included in their regular education setting. This study has significance for teachers, administrators, and schools by providing information regarding current general education, elementary teacher perspectives towards the inclusion of students with ED. Research has identified this as one of the barriers that exist within inclusion. Fuchs (2010) stated, "Teachers' beliefs about inclusion influence their beliefs about their own ability to educate diverse learners in the general education setting" (p. 30). By taking a closer look at these perspectives, we can better understand the concerns that exist about the inclusion of students with ED, what the perspectives are on the other barriers that exist, and supports that are needed.

\section{Theoretical Framework}

There are three theoretical frameworks that I draw from in my research: postpositivism, social constructivism, and disability inquiry. According to Creswell (2013), postpositivist researchers view inquiry as logically related steps. For me, those logical steps included the literature review and the completion of interviews. Postpositivist researchers also believe in obtaining multiple perspectives from participants (Crewswell, 2013). To the postpositivist researcher, there is not a single 
reality. I believe firmly in this. The experience will be different from different points of view and to truly understand it, I must get multiple perspectives on how teachers experience the inclusion of students with ED. Social constructivism also believes in multiple realities and multiple interpretations of those realities from those around them (Andrews, 2012).

"In social constructivism, individuals seek understanding of the world in which they live and work" (Creswell, 2013, p. 24). I work in the field of education and desire to understand more clearly the phenomenon of including students with ED. Social constructivist researchers ask more broad and general questions and aim to increase general understanding of the situation. I did not create targeted, narrow questions, but rather asked broader questions. One of the ways that social constructivist researchers do this is by incorporating stakeholders' perspectives. In the case of my research, the stakeholders that I am incorporating are the general education teachers. Their classroom is one where inclusion will take place.

Social constructivism is a part of disability inquiry as well. Disability inquiry looks at the meaning of inclusion in schools (Creswell, 2013). Using this theory, I will look at the environmental response to individuals with a ED disability within a general education classroom. Researchers who use disability theories focus on a disability as a part of differences in humans, not as a shortcoming. This difference is created from society's response to individuals (Creswell, 2013).

\section{Statement of Position}

As a researcher, I must recognize that my background will shape my

interpretations. As a result, I wish for my reader to have a clearer understanding of what 
my background is. I have been working in education for 13 years. Of those 13 years, 9 were spent as a special education teacher and 4 were spent as a behavioral consultant. Even before those 13 years began, as an undergraduate, my passion for teaching stemmed from working with students with ED. A portion of my current role as a behavior consultant revolves around the inclusion of students with ED or behavioral difficulties. I believe in the inclusion of students with ED with the appropriate supports and resources to the maximum extent possible. Through my experience as a behavioral consultant, I have witnessed successes and failures when it comes to inclusion. The passion for working with students with ED and the experiences with inclusion that I have witnessed led me to investigating the supports and barriers that existed with inclusion of students with ED. The information that I found there led me to the desire to complete a qualitative study on the perspectives' of general education, elementary school teachers on the inclusion of students with ED. My hope in performing this study was that I could find more supports that could be provided and understand the barriers with greater depth. 


\section{CHAPTER II}

\section{LITERATURE REVIEW}

\section{Introduction}

While legislation and litigation is encouraging inclusion nationally, $38.1 \%$ of the students with ED spend less than $40 \%$ of their day in a regular education classroom. Research demonstrates that there are several barriers to inclusion. This chapter provides an overview of literature related to the perspectives about inclusion, the impact of it, the barriers that exist, and the supports that are needed. First, I review the literature as it pertains to perspectives on inclusion. Next, I review the literature as it pertains to the perspectives on the inclusion of students with ED. Then, I present an overview of literature on the impact of inclusion academically on students with disabilities and students without disabilities. Finally, I review the literature on the overall barriers and supports to inclusion.

Literature for the current study was obtained through extensive computer database searches, such as Educational Resources Information Center (ERIC), ProQuest, and PsychINFO. I searched for peer-reviewed articles, dissertations, and books from 1990 to the present, using combinations of the key search terms of inclusion, history of, education, students with social emotional disabilities, students with disabilities, teacher perspectives, administrator perspectives, impact, effectiveness, education, special education, general education, emotional disturbances, and elementary schools. Initially I did not limit my search to specific dates, but as I started researching I found that literature 
in the United States prior to 1990 referred more to mainstreaming than inclusion. The year 1990 was when IDEA was passed and a least restrictive environment became a requirement. Internationally, even current literature uses the terms mainstreaming and integration. Looking at the inclusion of students with disabilities internationally is complicated because countries differ in how they define inclusion and emotional disturbances. It is also difficult because countries are at different phases when it comes to whether they are including, integrating, or mainstreaming students with disabilities. Inclusion, integration, and mainstreaming are not the same. I also used ERIC's EBSCOhost to look through back issues of Beyond Behavior from 2003 to present and Behavioral Disorders from 2003 to present. The oldest back issues on ERIC's EBSCOhost were from 2003. I also looked at articles that were in the reference section of articles that I read. I utilized the assistance of the subject matter librarian at Illinois State University. In all, this literature review will incorporate 12 peer-reviewed articles, 4 dissertations, and 2 books.

\section{Perspectives on the Inclusion of Students with Disabilities}

\section{Teacher Perspectives}

To begin the task of addressing the perspectives that educational professionals hold towards inclusion, I must first understand these perspectives. Research has investigated general education teachers' perspectives towards inclusion as a whole. General education teachers felt that the extra accommodations needed for the inclusion of students who were lower functioning is time consuming (Fuchs, 2010). This was accompanied by a feeling that administrators had unrealistic expectations of what general education teachers could accomplish for students with disabilities (Fuchs, 2010). The 
extra time required to supplement the curriculum for accommodations makes general educators apprehensive of inclusion (Ross-Hill, 2007). General education teachers were more resistant to the inclusion of students with maladaptive behaviors, whom teachers viewed as "problem students that require more time and attention" (Reasons, 2005, p. 20). Faced with what they viewed as greater needs of the students with disabilities, the general educators in Reasons's (2005) study expressed feelings of being overwhelmed and confused. "General education teachers often believe that they lack the skills and training to effectively implement inclusion" (Hoffman, 2006, p. 112). These findings lend support towards training being a component needed to make inclusion a success. A needs assessment should be conducted to tailor the training to the needs of the school so the general education teachers do not feel that the training is simply a waste of time (Fuchs, 2010).

Overall, however, there is a mixed attitude among general education teachers towards inclusion (Ross-Hill, 2007). When Andreasen (2014b) interviewed 9 teachers from different regions within the United States, she determined that overall there was support for inclusion as long as the placement was considered on an individual basis. Teachers identified that general education students are role models for appropriate behaviors (Andreasen, 2014b). Hoffman (2006) concluded that general education teachers were more neutral towards inclusion. Hoffman attributes this to the level of support general education teachers receive from special education teachers. Even the teachers with positive attitudes reported apprehension related to the behavior of the students with disabilities (Ross-Hill, 2007). 


\section{Administrator Perspectives}

Horrocks, White, and Roberts (2008) surveyed the attitudes of 571 principals in Pennsylvania public schools regarding placement for children with autism. Most principals had a more positive attitude in general for the inclusion of children with disabilities. The principals believed there was a need for staff development for inclusion to succeed. Horrocks et al. (2008) wrote, "Positive attitudes of key school personnel are seen as critical prerequisites for successful inclusion” (p. 1471). Elementary principals were more likely to recommend higher levels of inclusion if they held the belief that children with autism could be included and had previous positive experiences with inclusion (Horrocks et al., 2008). Horrocks et al. also noted that "principals were less likely to recommend high levels of inclusion for children with autism" (p. 1471) when the description of the child included social detachment. The reason this is interesting is that for some students with ED, social detachment is a component of their disability. The principals also felt that, for successful inclusion, teachers had to especially be prepared for the behavioral manifestations of autism because these behaviors could result in estrangement from others (Horrocks et al., 2008). The administrators in the study believed that inclusion was more successful for children with milder disabilities (Horrocks et al., 2008).

\section{Perspectives on the Inclusion of Students with Emotional Disturbances (ED)}

Research has looked at the perspectives on the inclusion of students with ED through both the points of views of administrators and teachers. Though the eight administrators throughout the United States in Andreasen's (2014a) study expressed support for inclusion, the amount of support varied. One administrator believed that 
inclusion was beneficial, but not for every child. This administrator specifically brought up students with ED as an example of students that would benefit from a more restrictive setting until the student demonstrates "the ability to comply with the rules in a segregated safe environment" (Andreasen, 2014a, p. 2). The administrator goes on to express that the success of inclusion for students with ED hinged on the proper supports being available. Another administrator in the study believed that all should be included, regardless of their disabilities (Andreasen, 2014a). This administrator felt that being included within the regular education environment helped students with disabilities to feel accepted.

In 1999, Heflin and Bullock decided to take a closer look at general and special education teachers' perspectives towards the inclusion of students with emotional disorders within the classroom. I n their study, Heflin and Bullock (1999) stated little is known about teachers' perspectives because they are generally a nonvocal and nonpublishing group. According to Heflin and Bullock, few teachers publish peerreviewed studies. This missing information was critical because "what makes the difference between success and failure is the attitude of the school personnel" (Heflin \& Bullock, 1999, p. 105). Heflin and Bullock interviewed nine general education teachers and nine special education teachers that ranged from elementary school to high school. They found that, when talking about inclusion of students with ED, general education teachers reported skepticism and fear (Heflin \& Bullock, 1999). Part of this skepticism and fear surrounded supports that teachers felt would only be put in place for an initial trial period, but would then be removed. Both general and special education teachers in the study reported barriers of (a) insufficient support and training, (b) nonproportional 
ratios of teachers to students, (c) being unable to meet the included students' educational needs, (d) behavior management, (e) time to make curriculum modifications, and (f) time to collaborate (Heflin \& Bullock, 1999). According to Heflin and Bullock, "100\% of the professionals believed that full inclusion would not serve the needs of all students" ( $p$. 107). One of the general education high school teachers stated that, "Full inclusion is laudable in theory, but falls short in practice" (Heflin \& Bullock, 1999, p. 107).

The feeling of fear that Heflin and Bullock (1999) reported on in their study has been supported by a more recent dissertation. Reasons (2005) found in a qualitative case study that general education teachers felt loss and fear when faced with the inclusion of students with ED and felt that the student's disability was a hindrance to successful inclusion. In particular, Reasons's study of five white female teachers in a Pennsylvania school district identified that the teachers felt neglected because there was not help available when working with students with ED. Teachers reported having fear of losing control of the classroom due to the lack of support and training (Reasons, 2005). This fear carried into a feeling of loss over the inability to get through to students with ED and to properly educate all of their students (Reasons, 2005). For some of the general education teachers, it led to a feeling of entrenchment and personal hardship and oppression. Reason called for the educational community to address these feelings. However, this study had two significant limitations. First, Reasons considered herself as one of the participants in the research study and included her own stories in the analysis of the data. Secondly, Reasons states that when the participants struggled to express their own stories of loss and fear, she would not only listen to their stories, but also share her own stories where she had felt similarly in the past (Reasons, 2005). This could have 
influenced the participation of others within the research study and greatly compromise the study.

Internationally, the subject of perspectives of the inclusion of students with ED is also getting attention In Canada, Drysdale, Williams, and Meaney (2007) completed a literature review on international studies by conducting a two-phase mixed methods research study. In phase one, they completed semi-structured interviews with five teachers and used the information from those interviews to create a survey. In phase two, 53 teachers completed the survey to look at teachers' perspectives on successful integration. In the literature review portion of their research, Drysdale et al., (2007) discuss that successful inclusion requires that teachers have a positive attitude towards both the students with disabilities and the policy of inclusion. They express that, when confronted with students with more extreme behavioral disorders, teachers may be initially hostile towards the inclusion (Drysdale, Williams, and Meaney, 2007). This attitude can be exacerbated by a lack of resources. Their research recommends that policies for inclusion should focus on developing positive teacher attitudes and training teachers in strategies for working with students with behavioral disorders (Drysdale et al., 2007). Internationally, studies suggest that integration policies should "focus on the development of positive attitudes in teachers and in teacher training" (Drysdale et al., 2007, p. 37). Drysdale's et al.'s data analysis discusses different challenging behaviors that general education teachers had to face and different strategies those teachers were familiar with. It does not, however, discuss what teachers' perspectives were.

In Scotland, MacFarlane and Woolfson (2013) conducted a quantitative questionnaire of general classroom teacher in mainstream schools. MacFarlane and 
Woolfson concluded that teachers who had more positive beliefs and higher levels of behavioral control had more of a desire to engage in the inclusion of students with ED. The data also showed that teachers with greater experience had less of a willingness to work with children with ED. MacFarlane and Woolfson (2013) stated, "Teacher perception of their principals' expectations was identified as the only significant predictor of teacher behavior" (p. 51). In MacFarlane and Woolfson's (2013) study, teachers who had more positive beliefs and had a perceived higher level of control reported that they would be more likely to promote the inclusion of students with ED within the general education classroom.

\section{Impact of Inclusion}

\section{Students with Disabilities}

If one is examining the perspectives on inclusion, one must also take some time to discuss what is the impact of inclusion. Peetsma, Vergeer, Roeleveld, and Karsten (2001) looked at the development of primary-aged students in mainstream and separate special education classrooms over two and four year periods in the Netherlands. The students with disabilities had either learning and behavioral difficulties or mild mental intellectual disabilities. Peetsma et al., (2001) found that, after two years, students with learning and behavioral difficulties that were included in the mainstreamed classrooms made more progress in mathematics than students in separate special education classrooms. Over the four-year period, the students with disabilities in the mainstream environment made more overall academic gain than students within separate special education classrooms (Peetsma, Vergeer, Roeleveld, \& Karsten, 2001). 
Peetsma et al., was not the only researcher to look at the impact of inclusion on students. Scruggs, Mastropieri, and McDuffie (2007) completed a metasynthesis of 32 qualitative research studies. Though they do not discuss which disabilities were included in each of the studies, Scruggs et al., do discuss the impact that inclusion had on students with disabilities. Students with disabilities are reported to benefit from exposure to peer modeling of appropriate behavior (Scruggs, Mastropieri, \& McDuffie, 2007). The research also demonstrated that students with disabilities received additional attention when there were co-teachers within the classroom. Research supports the conclusion that inclusion is beneficial for students with disabilities.

\section{Students without Disabilities}

Concerns might exist, however, on the impact of including students with disabilities within the regular education environment on students without disabilities. Dessemontet \& Bless (2013) assessed this impact for the inclusion of students with mild or moderate intellectual disabilities. To do this, they completed a quasi-experimental study with two sample groups of 202 pupils (Dessemontet \& Bless, 2013). One group had students with mild or moderate intellectual disabilities included and the other group had no included children with special educational needs. Over a year, the study concluded that there was "no statistically significant difference between the progress of low-, average-, and high-achieving pupils in classrooms with or without inclusion" (Dessemontet, \& Bless, 2013, p. 27). Dessemontet and Bless's (2013) study concurred with the findings of research that was in a literature review by Kalambouka, Farrell, Dyson, \& Kaplan (2007) that included numerous studies from the United States. 
Kalambouka et al., (2007) reviewed 26 research studies. These studies looked at the impact of including students with a variety of disabilities in mainstream schools. Overall, $81 \%$ of the studies reported positive or neutral effects for the students without disabilities (Kalambouka, Farrell, Dyson, \& Kaplan, 2007). Some of the studies that found positive or neutral effects included the effects of the inclusion of students with behavioral difficulties (Kalambouka et al., 2007). Kalambouka et al. did bring attention to the fact that 21 of the studies were completed in in primary schools within the United States. They also wrote that many of the studies within the review had the main focus of the impact of inclusion on the students with special education needs and a minor focus on the impact of inclusion on the students without disabilities (Kalambouka et al., 2007). Seven of the 26 studies reviewed by Kalambouka et al. were more recent than 1990, were written on primary schools, and included students with ED in the sample population of students with disabilities. Of those seven, four studies reported the inclusion of students with a variety of disabilities had a neutral impact for students without disabilities and three studies reported the inclusion had a positive impact (Kalambouka et al., 2007).

In their metasynthesis, Scruggs, Mastropieri, and McDuffie (2007) discuss the impact on students without disabilities when students with disabilities are included in a co-teaching setting in their metasynthesis. Some teachers reported an increase in cooperation among the students (Scruggs, Mastropieri, \& McDuffie, 2007). Many of the reports demonstrated academic benefits which were attributed to having the extra teacher present for co-teaching (Scruggs et al., 2007). Co-teachers even reported that the coteacher collaboration served as a social model for students to follow. Combined, the 
research supports inclusion as being beneficial for students with disabilities and positive or neutral for students without disabilities within the inclusive setting.

Despite the promising reports on inclusion, placement and exit patterns for students with ED are concerning. Landrum, Katsiyannis, and Archwamety (2004) analyzed data from the Annual Reports to Congress on the Implementation of the Individuals with Disabilities Education Act for the years 1989 to 1998 and found a correlation between exit patterns and school placement. What they discovered was that separate class placement was the most common placement option for students with ED and "graduation with a diploma was most closely related to school placement variables" (Landrum et al., 2004, p. 147). For students with ED, placement within a separate class was negatively correlated with graduation with a diploma (Landrum et al., 2004). Perhaps even more concerning is the fact that, despite the results reported by Landrum et al. and the time that has passed since Landrum et al.'s study, $47.8 \%$ of students with ED in Illinois spend less than $40 \%$ of their day within a regular education classroom (U.S. Department of Education, 2014). Barriers exist that are preventing inclusion from being successfully implemented.

\section{Overall Barriers to Inclusion}

Past research demonstrates that there are several barriers to the inclusion of students with disabilities from the special education and general education teachers' perspectives. Orr (2009) writes in her qualitative research study that she discovered three distinctive themes for barriers to inclusion from a special education teachers' perspective: “1) negative attitudes of general education teachers, 2) lack of knowledge, and 3) lack of administrative support” (p. 232). Fuchs (2010) identified a lack of administrative 
support, a lack of support from special education and support staff, and a lack of preparation in pre-service programs as barriers experienced by general education teachers. The fifteen special education teachers in Orr's study reported that general education teachers' attitudes, which ranged from hostile to a simple lack of enthusiasm, carried over into the interactions with students. One teacher in this study stated that some general education teachers were openly negative towards students with disabilities within the general education setting. The special education teachers reported that general education staff had reservations about how inclusion would work within a general education setting (Orr, 2009). The special education teachers in Orr's study also expressed that general educators often had a territorial response to teaching that interfered with collaboration. Meanwhile, the five general education teachers in Fuchs' (2010) study felt that the burden for instructional planning, grading, and accommodations was placed solely on the general education teacher. The general education teachers felt there was an unequal distribution of responsibilities and duties. The general education teachers reported that there was no assistance from the special education staff in making accommodations for the students with disabilities (Fuchs, 2010). The lack of support creates a feeling of tension between the general education and special education teachers.

Both studies stated that administrative support had a large impact in the support for or fight against inclusion within a school (Fuchs, 2010; Orr, 2009). Specifically, the participants in both studies brought up a concern with administration not providing teachers with the opportunity to plan for instruction and collaboration together. Orr (2009) reported that lack of administrative support may be linked to state test scores and a concern over how inclusion impacts these scores. For the general education teachers in 
Fuch's (2010) study, the lack of administrative support impacted areas such as "inservice education and training, collaboration and planning time, and shared duties" (p. 30). Orr (2009) called for administrators to develop district- and school-wide inclusion

philosophies to address feelings that inclusion was not supported within the district. Both Orr and Fuchs stated that there was a lack of pre-service preparation regarding inclusion for the general education teacher and special education teacher, though Orr does not identify this as a specific theme of the barriers. The general education teachers in Fuch's (2010) study reported that the lack of preparation negatively impacted their ability to successfully meet the needs of students who were being included within the general classroom setting. In both Orr's and Fuchs' studies, it was noted that teacher attitudes can have a large impact on the success of the inclusion of students with disabilities. This is consistent with the literature discussed above regarding how the attitudes of general education teachers can be a barrier to the inclusion of students with disabilities (Andreasen, 2014a; Andreasen, 2014b; MacFarlane \& Woolfson, 2013).

In other research studies, administrators have also identified barriers to inclusion. Andreasen's (2014a) study of eight administrators' perspectives towards inclusion identified that barriers included: (a) money, (b) time, (c) teacher personalities, (d) teacher perspectives, (e) parent misperceptions, and (f) lack of training. The administrators in Andreasen's study discussed how the lack of money could result in loss of paraprofessionals and how it was difficult to squeeze out time for teachers to collaborate. Many of the themes that were present in Orr's and Fuch's studies were also present in Andreasen's interviews with administrators. Andreasen (2014a) discussed that every administrator touched on how important understanding and meeting teacher needs was in 
encouraging inclusion within the school because "their teachers are the backbone of the school" (p. xxii). Teacher attitudes greatly impacted the success of inclusion within the school.

Hu and Roberts (2011) also identified many similar barriers including: (a) lack of resources, (b) lack of skilled teachers, (c) the need for support staff, (d) parent views on inclusion, (d) teacher attitudes, and (e) a lack of training. It is important to note that this study was conducted in China, which has differing cultural views on disability as well as differing attitudes on inclusion that the U.S. system does. Regardless it is interesting that they face similar barriers. There is a critical shortage in China of teachers who are skilled and prepared enough to teach inclusive classrooms. The administrators expressed a need for training to include on-site on-going collaboration and specific feedback (Hu \& Roberts, 2011). Administrators expressed that teachers, while sympathetic to the needs of students with disabilities, were reluctant to include children with disabilities within their classrooms. To address the barrier of teacher attitudes, more research needs to be completed to understand the perspectives of general education teachers, especially in regards to the inclusion of students with ED.

\section{Overall Supports to Inclusion}

Research has identified multiple supports that are needed for the inclusion of students with disabilities (Andreasen, 2014a; Andreasen, 2014b; Fuchs, 2010; Horrocks, White, \& Roberts, 2008; MacFarlane \& Woolfson, 2013; Nelson, 2000; Orr, 2009; Reasons, 2005; Ross-Hill, 2007). One support is the adoption of a district- or schoolwide, pro-inclusion philosophy (Orr, 2009). These policies help promote encouragement for practices that support inclusion. Special education teachers in Orr's (2009) study 
reported that the implementation of district-wide, pro-inclusion philosophies created an atmosphere that had a team approach towards the success of all students. School administration has a large impact on the development and implementation of these philosophies (Andreasen, 2014b; Horrocks, White, \& Roberts, 2008; MacFarlane \& Woolfson, 2013; Nelson, 2000; Ross-Hill, 2007). Another support was fostering positive attitudes in general education teachers. General education teachers needed to be accepting and accommodating of special education students (Orr, 2009). They needed to be willing to communicate both with the students and with the special education teacher (Nelson, 2000; Orr, 2009; Ross-Hill, 2007). Special education teachers report that they value general education teachers who are willing to communicate often, be collaborative, and ask for advice about accommodations (Orr, 2009). Finally, a partnership between general education and special education teachers can be a significant support for the inclusion of students with disabilities. Orr (2009) stated that this needed to be a shared partnership that has a focus of respect for the expertise of each educator. Orr pointed out that one way administrators could foster this partnership would be to include common planning time for the collaboration between the general educator and the special educator. The administrators in Andreasen's (2014a) study expressed that common planning time was ideal, if difficult to implement.

Some research also calls for a change in the preservice education of both general and special education teachers to be more focused on collaboration and inclusion (Orr, 2009). Fuchs (2010) states that the preservice programs need to prepare both general education and special education teachers to teach in inclusive classrooms. For teachers who are finished with their preservice education, training could also occur as part of 
professional development programs within a school district (Andreasen, 2014a; Andreasen, 2014b; Orr, 2009; Reasons, 2005; Ross-Hill, 2007). This training should cover information such as "the characteristics of children with special needs, the individual education program, special education law, strategies for adapting instruction, collaboration, behavior management, conflict resolution, anger management, and discipline" (Reasons, 2005, pp. 54-55). It should be on going and offer specific feedback as far as how inclusive practices within the school are being implemented (Andreasen, 2014a). Research has demonstrated that, with the proper training, teachers may have more positive feelings towards inclusion (Ross-Hill, 2007). Once teachers concerns about inclusion have been more clearly identified, training can occur to attempt to address those concerns.

\section{Summary}

Research has demonstrated that inclusion has positive effects on academics for students with disabilities (Baker et al., 1994; Peetsma et al., 2001). Specifically, for students with ED, placement in a more restrictive environment is negatively correlated with graduation with a high school diploma (Landrum et al., 2004). For students without disabilities, inclusion has been found to have a positive or neutral impact (Dessemontet \& Bless, 2013; Kalambouka et al., 2007). Yet, for students with ED, a large percentage of students are serviced with less than $40 \%$ of their day in a general education environment (U.S. Department of Education, 2014). Many barriers and supports for inclusion have been identified, including the level of administrative support, resources, and teacher attitudes towards inclusion. 
For my research study, the barrier that I am focusing on is that of the general education teachers' attitude toward inclusion. MacFarlane and Woolfson (2013) report, "Mainstream teacher attitudes may be a contributory barrier to successful inclusive practices" (p. 46). Research shows that one of the supports for inclusion lies in the attitudes of general education teachers (Orr, 2009). Overall, the attitude of general education teachers towards the inclusion of students with disabilities is mixed, with attitudes ranging from positive to a simple lack of enthusiasm to hostile (Andreasen, 2014b; Orr, 2009). The research that has been completed within the United States demonstrates that general education teachers' attitudes towards the inclusion of students with ED are marked by skepticism, feelings of fear and a feeling of loss (Heflin \& Bullock, 1999; Reasons, 2005). The research that has been completed calls for further investigation and identification of the barriers and supports to inclusion, particularly that of teacher attitudes (Fuchs, 2010; MacFarlane \& Woolfson, 2013; Orr, 2009; Ross-Hill, 2007). 


\section{CHAPTER III}

\section{METHODS}

\section{Research Design}

Some researchers have utilized a qualitative approach when examining teachers' perceived barriers and supports to inclusion for all students with disabilities (Andreasen, 2014b; Fuchs, 2010; Orr, 2009). Fuchs (2010) states, "It is clear from the research that further qualitative investigation of the perceived barriers associated with inclusion is paramount” (p. 31). I used a qualitative research design to look closely at the phenomenon surrounding general education and elementary teachers' perspectives on the inclusion of students with ED. Phenomenological research surfaced in the early twentieth century based on the works of Husserl (McPhail, 1995). Husserl argued that life consisted of two types of "reality: (1) noumenon - being in reality itself and (2) phenomenon - appearance of reality in consciousness" (McPhail, 1995, p. 160). According to phenomenologists, the primary focus of study in human sciences should be on the description of phenomena. Thus, phenomenology is defined by how something, a phenomenon, is experienced by a participant. The philosophy behind phenomenology has four main assumptions: (a) an essential ingredient of human life is consciousness; (b) in that consciousness, there is not a substantial difference between objectivity and subjectivity; (c) consciousness is temporal and carries elements of past experiences and anticipations of future experiences; and (d) human beings' consciousness is what creates the world and the culture that surrounds them (McPhail, 1995). I used a 
phenomenological approach to study elementary, general education teachers' attitudes towards the inclusion of students with ED.

Phenomenological studies describe "the common meaning for several individuals of their lived experiences of a" phenomenon (Creswell, 2013, p. 76). Because of this approach to the study, all of my participants have worked with the inclusion of students with ED. The purpose of phenomenology is to describe the nature of the human experience. My phenomenological research was completed through the use of semistructured, face-to-face interviews. Phenomenological studies typically include interviewing participants who have experienced the phenomenon (Creswell, 2013). The purpose of using the interview is to investigate directly social variables (Holliday, 2000). By being semi-structured, the interview allows the researcher to be led into "unforeseen areas of discovery within the lives of the people" that are participating in the interviews (Holliday, 2000, p. 5). These interviews were conducted face-to-face. Because my study is phenomenological, it focused on a heterogeneous group of teachers who have experienced the inclusion of students with ED. Creswell (2013) states that this group should be between 3 to 15 individuals. The goal of this research design was to be exploratory. This means that the research was designed to provide a better understanding of elementary school, general education teachers' perspectives.

\section{Instrument}

The instrument that I used was a semi-structured interview protocol, which consisted of nine open-ended questions and was inspired by Orr's (2009) interview study of 15 special education teachers. During these interviews, in addition to discussing what inclusion looked like in different schools, she identified themes about barriers and 
supports to inclusion. Similarly, I interviewed different teachers about inclusion. Parts of my research questions were designed to look at what are perceived barriers and supports for inclusion. Unlike Orr's study though, I interviewed general education teachers and discussed their views on inclusion.

As described in Table 1, each of my questions relates to at least one of the research questions for the study. Using a strategy similar to Orr (2009), questions one, three, and five were designed to gain information about demographics and the experiences that the teacher has regarding inclusion. Orr's (2009) study used the interview data to analyze what barriers and supports existed for inclusion of students with disabilities. Questions four, seven, and eight were designed to gather information about what barriers and supports the general education teachers perceive exist. This allows me to compare my results to past research on barriers and supports for inclusion (Andreasan, 2014a; Fuchs, 2010; Horrocks et al., 2008; Hu \& Roberts, 2011; MacFarlane \& Woolfson, 2013; Nelson, 200; Orr, 2009; Reasons, 2005; Ross-Hill, 2007). Question two and six were designed to look at the general education teachers' perspectives towards the inclusion of students with disabilities and the inclusion of students with ED. Answers to questions two and six will be compared to other research on teacher perspectives towards inclusion. 
Table 1

Interview Questions

\begin{tabular}{lr}
\hline \multicolumn{1}{c}{ Interview Question } & Research \\
\hline 1. What is your teaching experience? & 1 \\
2. What are your views about inclusion? & 1
\end{tabular}

3. What experiences have you had with 1

inclusion in your classroom?

4. What barriers have you experienced with 2

inclusion?

2

5. What experiences have you had with the 1

inclusion of students with emotional

disturbances within your classroom?

6. What are your views on the inclusion of 1

students with emotional disturbances?

7. What barriers do you feel would be

experienced during the inclusion of

students with emotional disturbances?

8. What supports would you like to see

3 provided?

9. What further information would you like $\quad 1,2,3$ to share on this topic?

My questions are also drawn from a phenomenological perspective. Question five asks participants what their experiences have been. According to Creswell (2013), asking what experiences have been is part of what helps focus attention on gathering data to understand the participants' common experiences with the phenomenon.

$\mathrm{Hu}$ and Roberts (2011) interviewed 12 directors of pilot inclusion preschools in China. I felt that the final question in $\mathrm{Hu}$ and Roberts interview allowed for a sense of 
closure at the end of the interview. The inclusion of question nine was designed (a) to provide the participants the opportunity to expand on any of the other questions and (b) to provide the participants closure at the end of the interview. Interviews took approximately 22 - 45 minutes. I asked questions and followed them with probing questions, if further information was needed. A copy of the interview protocol is in Appendix B. Interviews were audiotaped and then transcribed following the interview.

\section{Research Setting}

This exploratory study was conducted in an urban school district in Central Illinois. According to the Interactive Illinois Report Card (IIRC), this school district provides services to 8,535 students at an average cost of $\$ 4,538$ per pupil. Though the students are not participants, the demographics about the students help give a better picture of the school district. The students range from Black (46.3\%), White (39.1\%), Hispanic (3.0\%), Asian (0.8\%), American Indian (0.2\%), and Multi-racial (10.5\%). The school district has $76.1 \%$ of students falling within low-income families. $14.7 \%$ of students within the school district have been identified as having disabilities. In the past academic year, the school district had $38.9 \%$ of students meet or exceed standards in reading and mathematics on the ISAT tests. There are a total of 20 schools within the school district. 15 of those schools are elementary schools. One of the elementary schools in the district houses the elementary program for students with ED that require alternative placements.

\section{Participants}

This school district in Central Illinois has approximately 204 general education, elementary school teachers. Five teachers were chosen as participants. These 
participants were general education, elementary school teachers who had experience with the inclusion of students with ED. Participants came from three schools within the district. Creswell (2013) recommends that qualitative researchers collect data in a natural setting for the people under study. Participants were offered the opportunity to be interviewed in a setting that the participant felt most comfortable. All participants chose to be interviewed in their classroom. Table 2 provides demographic information about the teachers. For the purpose of reporting on the data and analysis, participants have been given pseudonyms. Between the participants, teaching experience ranged from 5 to 15 years. One of the teachers had never co-taught with a special education teacher, but the other four had. Teaching experiences ranged from teaching Kindergarten through $6^{\text {th }}$ grade. Amanda had been a special education teacher prior to becoming a general education teacher. Her experience with the inclusion of students with ED was as a special education teacher.

Table 2

Demographics of Participants

\begin{tabular}{lllll}
\hline Teacher & Years Teaching & $\begin{array}{l}\text { Co- } \\
\text { Teaching } \\
\text { Experience }\end{array}$ & $\begin{array}{l}\text { Grades } \\
\text { Taught }\end{array}$ & School \\
\hline Amanda & 6 & Yes & $\mathrm{K}-6$ & 1 \\
Rachel & 9 & Yes & $\mathrm{K}, 2^{\text {nd }}$ & 2 \\
Michelle & 15 & Yes & $2^{\text {nd }}, 3^{\text {rd }}$ & 3 \\
Beth & 7 & Yes & $4^{\text {th }}, 5^{\text {th }}$ & 3 \\
Rebecca & 5 & No & $1^{\text {st }}, 6^{\text {th }}$ & 1 \\
\hline
\end{tabular}




\section{Procedures}

I first completed the Institutional Review Form for Illinois State University and for the district where the research was conducted. Once I obtained permission from the school district and the Institution Review Board for Illinois State University, I recruited teachers by posting a flyer on the notice board in the teacher lounges for the elementary schools within the school district. I also mailed a flyer to each of the general education, elementary school teachers within the district. Information on who these teachers are was obtained using the district's website. Participants were informed that their participation is voluntary, and they were able to choose to withdraw from the study at any time. They were also informed that their perspectives would be appreciated as important data for the

study. Participants were compensated for their participation in the form of a $\$ 20$ gift card to coffee shop.

Seven teachers responded to the flyer through email, volunteering to participate in the study. Informed consent letters were sent to each of the seven volunteers. Five teachers returned their informed consent letters. Interviews were scheduled in a setting that was most comfortable for the participant. All teachers chose to be interviewed within their classroom. A reminder email with the time, date, and location of the interview was sent two days prior to the interviews. Interviews took approximately 22 45 minutes. After the interviews were completed, data from the interviews was transcribed and coded. I reviewed audio recordings and transcripts multiple times to ensure accuracy of the transcriptions. Transcripts were coded and analyzed using nVivo qualitative data analysis software. 


\section{Data Analysis}

To increase instrument reliability, prior to the data being coded, participants were given a chance to review the transcripts. Participants were able to verify what they stated in the interviews. This is a technique that was also used by Orr (2009) and Fuchs (2010). All five participants verified the transcripts.

I coded the transcriptions using nVivo 11 software and looked for themes. The nVivo 11 software is designed for qualitative and mixed methods researchers. It helps the user organize and analyze qualitative data and look for themes within the transcripts. Initially, I used nVivo to code anything that fell within my research questions that was in the interviews. Then I compared the different codes, looking for overarching themes. I then had to analyze the themes, especially if there was a quote that fell under two themes, to determine which theme it best fit with.

Validity was assessed through peer review. A peer reviewed and edited my coding on the nVivo 11 software. The peer was familiar with the concept of inclusion and with the area of study of special education. He is currently working on his dissertation in the area of students with attention deficit hyperactive disorder and identity. Low-inference descriptors were used as well to increase validity. In order to use lowinference descriptors, I will use terms that are concrete as possible, which includes quotes from the interviews themselves. I discussed those themes and further questions, and also compared them to past research.

\section{Ethical Issues}

The study did not use any protected populations. Participants were chosen on a volunteer basis. The participants were given a consent letter prior to the interview stating 
that their participation in the study will have no influence on their evaluations in the future. The consent letter also stated that participation was voluntary and the participant could withdraw at any point during the interview without penalty. Participants' identities will remain confidential. During the interview, no names were used. Creswell (2013) recommends using composite stories so that individuals cannot be identified. As a result, rather than including the transcripts of the interviews themselves, quotes are used throughout chapters four and five to give composite stories on the way that teachers experienced the phenomenon of the inclusion of students with ED. Given that one of the questions asked about past experiences with students with ED, participants may have negative emotions brought up. The interviews were assigned a pseudonym and the researcher was the only person with access to the information of which person was associated with which pseudonym. After receiving feedback from the participants on the transcription of the interviews, any association with the participants name and pseudonym was erased to protect anonymity. Data is presented in the form of themes. The audio data was disposed of after the analysis for ethical reasons. 


\section{CHAPTER IV}

\section{RESULTS}

\section{Introduction}

This study examines general education, elementary school teachers' perspectives on the inclusion of students with emotional disturbances. Each section of this chapter answers one of the research questions that guided the study and is organized around the themes that emerged from the data within that research question.

This research explored the following questions:

1. What are the perspectives of general education teachers at the elementary level towards the inclusion of students with emotional disturbances?

2. What do general education teachers at the elementary level perceive as barriers to the inclusion of students with emotional disturbances?

3. What do general education teachers at the elementary level perceive as supports that are needed to assist the inclusion of students with emotional disturbances?

\section{Emergent Themes}

When using nVivo to help organize and code my data into separate themes, I identified the themes of perspectives, barriers, and supports. Within each theme, there were subcategories that appeared.

\section{Perspectives}

To address my first research question, I asked participants for information regarding their perspectives on the inclusion of students with ED. Overall the findings 
surprised me in that some were not consistent with previous research. Given the data that were present in past research, I expected to find only negative perspectives from the teachers that I interviewed (Heflin \& Bullock, 1999; Reasons, 2005). Instead, I found a mixture of positive and negative perspectives.

Positive perspectives. Four of the five participants interviewed expressed positive perspectives. These perspectives encompassed the benefit for including students with ED for teachers and for the students with ED. One of the participants expressed how working with students with ED is beneficial for teachers. In her interview, Rachel expressed that having students with ED in your classroom "makes you a stronger teacher that you have to deal with that. You have a better understanding of where the kids are coming from." Beth described how inclusion of students with ED was good for the students without disabilities, explaining,

It's good for the general ed students because they need to see that not everyone follows the rules. And like, people just don't always do what they're supposed to do. And you can't just always do what everyone else is doing.

For Beth, inclusion of students with disabilities was one way to give all students a realistic picture of the world and how people interacted.

Three teachers who expressed positive perspectives about inclusion of students with ED mentioned that it was especially beneficial for the students with ED. Amanda stated repeatedly that inclusion was important for students with ED for social reasons. She stated, 
They need to be with socially appropriate peers. So, as a ten year old, they should be working with another ten year old because, first of all, as a teacher I can tell you how a normal ten year old should act or you can actually see it first hand.

Amanda expressed hope that "maybe if these kids see socially appropriate behavior, maybe they're going to mimic the behavior." Amanda posited that inclusion meant that you did not segregate the students because, "You don't want them to be separate. You want them learning the skills of how to function in a classroom, how to function in life."

Rachel also mentioned that it was important for students to see that socially appropriate behavior. "It's good for the student to see other people that are on target and being good role models." She also stated that it was good "for the student's self-esteem" especially when "you're including them at a young age, the other students are a little bit more accepting because, you know, Jim's been with them."

Rebecca also spoke to social modeling when she stated, "They need that social interaction to know what's natural, what's normal, what's healthy." Rebecca was the most passionate, stating, "I feel every student has their equal right to an education just like the next person. This student, you know, emotional disorder or not has been handed a bad hand. They still deserve their education. They still deserve the best education that they can possibly have."

Negative perspectives. Though none of the participants expressed feelings of loss or fear as found by Reasons (2005) and Heflin and Bullock (1999), four of the five participants expressed concerns with different aspects of the inclusion of students with ED. Concerns ranged from that of the quality of teacher work environments and threats 
posed by the behavior of students with ED. Rachel expressed concerns over the working environment in inclusive classrooms, stating, "Well, I've had chairs thrown. I've had a yardstick picked up and thrown around. I've had desks tipped over. Students and staff members have had to deal with verbal abuse."

Rebecca stated that “once the teacher doesn't feel safe, once the other students aren't safe, then something more drastic needs to be put in place." Rebecca also expressed concerns over the classroom environment for students without a disability and the appropriateness of an inclusive placement, explaining, "If they [other students] come to school everyday and there is a kid throwing things, and they don't know if they're going to get hit. They don't know if they're going to get hurt. Their safety is also a concern."

These concerns extended to frustrations about the extra work. Amanda elaborated, saying "I think that we get to the point that we, as general education teachers, are so stressed out...the testing, the scheduling, the getting everybody to the next grade level...that we think, 'Oh, this is just one more thing!'” Michelle stated, "My problem with including kids like that is that I don't think we have the support. We really don't." In an age where student progress has an increasingly important role, much of the frustration was over seeing a lack of progress. Amanda said, "Like right now I have these behavior plans, and I fill out weekly sheets, and I turn them in to our social worker and I don't see growth...Where's the growth? There is no growth and that is really frustrating." Rebecca questioned, if there is a lack of progress, if the inclusive setting is the best for that student and for those around them. 
Not just keeping them in an environment where they're not going to thrive, where they're not going to move forward. Because all that's going to do is, not only hurt that student, but it hurts the rest of the class and it causes other students not to learn.

The biggest concern for Rachel was the process when a student with ED was not succeeding in the classroom. She explained,

I think when a student's not working out in the classroom, the process is very lengthy and it's very painful....and I think it's painful for the whole class, for that student, for the family, for the faculty...I just think it's too long of a process when there is a serious issue.

\section{Barriers}

My second research question looked at what general education, elementary school teachers felt were barriers to the inclusion of students with ED. When asked what they felt were barriers, the participants had several thoughts and ideas to contribute. When I looked at the interviews as a whole, four main themes emerged in the area of barriers: (a) safety, (b) student behaviors, (c) time, and (d) information.

Safety. Two of the five participants mentioned safety as being a barrier to the inclusion of students with ED. When she was asked about challenges for the inclusion of students with ED, Amanda was very clear on one of her concerns when she stated, "Safety...if they're explosive. Um, and not just safety for other kids...safety for themselves." At one point Amanda says, "I get nervous sometimes when the behaviors become explosive and they can cause harm to themselves or another student." Rebecca discussed the need for emotional safety for the other students within the classroom. "I 
don't like to feel like I don't have a heart...but I also have to think about the other 20some kids in the classroom. Not only think about their wellbeing, their education, you know, their emotional...they need to feel safe at school, too."

Student behaviors. Four of the five participants discuss the behavior of students with ED interfering with their inclusion. This barrier can be present because it leads to negative perspectives from other students. Amanda talks about it vaguely when she states,

You know, we don't announce, "Hey, this is so-and-so. They have EBD. They're going to be in our classroom." But at the same time, ten year olds, not dumb. They see, "Oh, he has a really quick temper." Um, they're going to think of him as mean, or a bully. Or they're going to think she is weird because she cries. Or, they're going to put their own associations with it.

Student behavior can also be a barrier for teachers who are unsure of what to do when a student is exhibiting that behavior. Beth explains, "But that's one big hurdle...that defiance and not wanting to do what they are supposed to do." When talking about Rebecca's experiences with a student with ED, she expresses how the behavior of a student with ED can cause a barrier for the teacher when it comes to figuring out how to work with the student.

He was a threat to himself more than he was a threat to the students in the class. But he still had his moments where he would pick up a chair and toss it out of frustration or throw his pencil box off his desk. And you know, even though those were very rare, it still is, how do you go about 
your day and let that not be a distraction when you don't have an assistant to help you in those situations?

Rachel describes it as being a barrier because of how the student's with ED behavior impacts the whole class, "I also feel that when it is hurting the majority of the classroom for one or two students to be in there when they are academically capable of being in the classroom, but for behavior reasons can't be in there." Rachel is unsure how inclusion can be successful when the student's behavior impedes learning for all students.

Time. One of the barriers that every participant identified when it comes to the inclusion of students with ED was that of time. Some of the time is in the work it takes in the planning to implement inclusion. Beth states, "In general, my biggest barrier is just how much work there is." Rachel also mentioned the time it takes for preparation. "Well, it's definitely the time management. It's also having to have differentiated material...and there's just not enough time already for what a teacher's expected to do." Part of the barrier of time is in balancing the time spent on the student with ED with the time spent with other students. Amanda describes that the other students "might feel neglected from the teacher because the teacher time might be spent more on making sure the student with EBD is comfortable and that the room kinda stays at like an even keel." Amanda feels that the impact of time is that "there's 20 kids in my room who feel like, 'I wish my teacher would know I was here. I wish my teacher wasn't spending so much time putting out fires." Amanda expresses the dilemma, saying, "It's balancing. How do I address the needs of one student compared to the needs of 26 at any given moment?...How can I meet their needs and then meet the needs of the other kids?" Even when they know that it will reach the students, it can be a struggle, as Beth describes, "I 
guess it's taking the time when I'm still dealing with the rest of the classroom to like, deescalate them or take the time to work one-on-one with them." Beth goes on to state, "I think time gets taken away from their learning." Rachel mentions, "Other students missing out because I have to correct a behavior or because one or two students need more of my time that then takes away from the whole group." She goes on to say, If it's just me, the time that I have little Jim in my group is great. But the other three groups that Jim's not in my group, and he's supposed to be doing the free for all, is usually not a free for all...it ends up with me stopping my group to do some type of discipline or some type of redirect, so then it affects everyone.

Rebecca states that the barrier of time is in "The disruption to other students...the disruption to lessons."

Another concern with time is that there was not enough time to do what was needed for the students. Amanda states, "There is not time to stop and redirect. There is no time to stop and put out the fire that you're about to start." Beth feels that, It just makes it hard...like sometimes I feel that, with those behavior kids, I could get through a lot more to them if I had 6 of them or 8 of them in a small group or a small classroom.

Michelle expresses that giving the student the time needed to address problematic behavior is not always possible. She states, "I can't fully address that behavior to the extent that I think they need because I have 23 other kids in the class that need my attention. So, a lot of the times, it's you have to leave." For Michelle, this lack of time is one of her challenges. 
Because, a lot of times, from what I see in my class or in classes

previously, a lot of them want attention. A lot of them want one-on-one contact. And, again, I can only give you so much. The time I have to devote is a challenge.

Information. The other area that was a particular challenge for Michelle, and Amanda, was that of information and what to do when you have it. Michelle elaborates, "A lot of times, I don't have enough information about the student to deal with them appropriately. It's...a lot of times, to me, it's I find by investigation.” Amanda expresses that the lack in communication is due to both doctors and parents when she states, "I think that doctors need to really communicate more with the school districts...parents need to disclose more information with teachers regarding medical diagnosis..." Amanda describes that she does not want to know everything.

So, as a teacher, no I don't need to know everything about their lives, but that is key information. Because, if he is oppositional defiant disorder, I would be treating him a whole lot differently because I would need to know, like, is this why we're resisting? Is this why we're doing something?

Michelle has different concerns when it is about information on students with disabilities. For Michelle, the question is what can be shared about the disability and how to effectively share it.

A lot of times you went into things where another student has said, "They hit me or they said something... something inappropriate." And how you deal with that... sometimes is...I can only tell them so much. And 
sometimes I see the barrier as being, they are in a classroom with say 23 other kids, and I can't let my 23 other kids know what is going on with him.

\section{Supports}

My third research question focused on asking teachers about what supports were needed to include students with ED. To overcome barriers, the participants interviewed expressed a desire to see three main areas of support: (a) planning for crisis, (b) professional development and training, and (c) staff.

Planning for crisis. Two of the participants, Amanda and Rebecca, mentioned the need for planning when supporting the inclusion of students with ED. Rebecca perhaps best summarized their views when she stated, "They still deserve the best education that they can possibly have. That's why we still need to have some kind of a plan.” Because, in Rebecca's words, “If you don't have a plan, you're going in blind, and you're not going to know how to react to the situations when they come." Different types of plans were mentioned. Amanda advocated for behavior plans,

Um, as far as managing behaviors, that is a day-to-day struggle still. It has gotten better. I have three on behavior plans. I have four who seek incentives from the social worker. So, I am able to provide them with an extra source that I'm not able to be for them, I guess is a good way to say. Rebecca vaguely talked about a behavior plan when she stated, "Coming in with a set plan. This is what's going to happen. If this plan's not followed, there are specific consequences. If this plan is followed, there could be rewards." She went on to say, "And it can train the teachers as well as have the student on a behavior plan." Amanda 
also mentioned having a plan for medication concerns, "If a child is not medicated, there should be a plan in place." Finally, Amanda mentioned the need for a plan in the event of a crisis within the classroom, "I think that they need to understand that the plan is in place for a reason. Um, if it escalates, we have an emergency button in this room."

Professional development and training. Two of the participants discussed the need for professional development and training to support the inclusion of students with ED. Rebecca stated, "We need more professional development on classroom management and handling the certain situations that may arise." Rather than the typical sit and learn model of professional development, both Amanda and Rebecca called for more of a hands-on training model. Amanda elaborated, "I want to see someone come in and just physically show me how you personally would de-escalate a situation where I would have a kid throwing a desk over how hard math is right now." She went on to say, "I would want a behavioral specialist to come in and model something for me because that is so valuable. Because I'm doing it right. I'm watching the data tracking. I'm seeing how it should be done." Amanda also asked for information on specific strategies to use with students when she stated,

I wish the community health agency would send a representative, sit everyone who works with the kid down, and be like, "Look, parent signed this agreement for me to share this following information." It doesn't have to be everything. Student has this. Here are some strategies you can use. If it escalates, this is what you do.

For Amanda, these strategies could even take the form of a recommendations packet. Amanda explained, 
If you need something, having that go to list of things you need. Like, “Oh, so you have a child who's nonverbal and aggressive. Here's what we do. We do this, this, and this. Oh, you know there's going to be a really cool workshop in two weeks on this. Let's go see it. I'll go with you."

Rebecca emphasized how the on-site training and professional development would help the teachers who have never experienced inclusion of students with ED before. She described, Just putting a child in a classroom that's new or that's never dealt with the situation before, um, can have the teacher being very...nervous? Very...that can turn them away from these kinds of inclusions. But if having someone come in who is a behavioral specialist, come in and say, this is what needs to be done, then a teacher can know these are the behaviors that they need to follow.

For Amanda and Rebecca, professional development is an important way to reach teachers who are working on including students with ED.

Staff. The one area of support that all five participants mentioned during their interview was that of a variety of support staff. Some participants expressed appreciation and a need of supportive principals. Beth stated, "I guess, thinking of my situation, my principal has always backed me up." Rebecca described her supportive principal, "We have a principal that's very understanding, very helpful, and jumps in whenever we need help. He doesn't just pass it off like it's not important." 
Many of the participants mentioned the importance of the social worker within the building for students with ED. Amanda explained, "And our social worker does take time to say, 'How's your day? How's it going?' and I think those check-ins are, like, super important to them." Michelle talked about how social workers are beneficial in helping other students accept the student with ED,

The social worker did a lesson on sexual inappropriate touching and things like that. And I think that if we, as educators or as a school system, if we address head on problems like that, I think it would help the kids in the classroom deal with it better.

Michelle spoke to the need for additional social workers, "We have one social worker, and we have, what, 250-260 kids in this school. And in my class alone there are maybe 5 kids that needs support, and they might get 20 minutes a week. That's not enough." Michelle goes on to say, "As I said before, we need more social workers." Multiple participants mentioned the need for paraprofessionals to work with students with ED. Amanda said plainly, "And so I think assistants are going to be needed to help kids with EBD in the classroom." Rachel spoke to how a paraprofessional could help, “An assistant can kinda help with that behavior. Keeping a particular child in line, I guess." However, Rachel also added a note of caution with the use of assistants, stating, Um...I've actually talked to a few colleagues about that and stuff. Because some people are like well they should have an assistant with that particular student. They should have a one-on-one assistant. Well, I think that draws more attention to that student, then it actually makes the oneon-one...that outweighs...yes, if the student had a one-on-one assistant, 
yeah, that's great, but still you're excluding them because everyone knows that person has an assistant.

Rachel advocated, instead, for the use of a co-teacher, explaining, Co-teaching where another teacher is in the room teaching reading, but teaching not just that student, but the majority... Mainly because the number of students to adults plays such a drastic impact on a regular student or a student that's needing extra assistance.

Rachel follows this with a request that the teacher "has a special ed background. I don't think that it would be beneficial to have two people that have two elementary ed degrees to be co-teaching in the classroom."

Three of the five participants brought up the need for additional behavioral consultants. Rebecca mentioned it first by saying, "I feel that those assistants and those behavioral specialists are very very helpful in introducing a child with these kind of behaviors to a classroom, and helping a teacher because not all teachers have experience in this issue." When asked what further information she would like to share, Rebecca put a lot of emphasis, saying loudly, "We do not have enough behavioral teachers! PERIOD! We do not have enough." Michelle stated that it would be helpful to have "even a behavior specialist, at least one or two in a building, to address issues...to come up with ideas...to even interact with them one-on-one." Amanda spoke the most about them, at first mentioning them, "They would check in several times and then that way, behavioral specialists can be like, 'Ok, I'm your intervention. Here I am. What do you want me to do?"”

And later Amanda went on to say, 
If they had more behavioral staff at the special education department that they could disperse, that would be helpful. So like your schools that are, like, higher low income...that have massive behavior issues...maybe a behavioral specialist they would split between that school and a lower behavioral problem school. Or if you have four lower behavioral problem schools, you're split between four schools. So it's kind of like that tech coach type idea where you would have a behavioral coach that would come in and really help with classroom management.

\section{Summary}

Amanda, Beth, Michelle, Rachel, and Rebecca volunteered to participate in an interview that took a closer look at the teachers' perspectives on the inclusion of students with ED. All of the participants had previous experience including a student with ED. The stories they told spoke to their views from experience of the inclusion of students with ED, the barriers that exist, and the supports that they would like to see provided. Discussion of the perspectives on inclusion included information on positive viewpoints; such as how beneficial it was for students with ED and for students without ED in the social modeling and opportunities for real life practice. Teachers believed also that it could be beneficial for teachers by making them stronger. But concerns were also raised in regards to the classroom environment and what to do when progress was not being made. Discussion about barriers revolved around four main areas: (a) safety for the students with and without ED and the teacher, (b) student behaviors and the impact they had on the classroom, (c) the time that was available to plan for and implement the inclusion and to devote to the student with ED, and (d) the lack of information about the 
disability that was provided to the teacher when it came to working with the student. The participants did not say that the barriers were insurmountable, however, instead focusing on the need for supports to overcome them. Planning for crisis was crucial for two of the participants in implementing inclusion. Others felt professional development and training would assist teachers who were unfamiliar with how to include students with ED. All of the participants mentioned considerate and collaborative staff as a necessary provision to help with successful inclusion. 


\section{CHAPTER V \\ DISCUSSION}

\section{Overview}

Inclusion is a civil and an educational right. This has been demonstrated through both legislation (The Vocational Rehabilitiation Act of 1973, ADA, and IDEA) and litigation (Brown v. Board of Education (1954) and Mills v. Board of Education (1972)). Research has demonstrated a negative relationship between graduation with a diploma and placement within a more restrictive setting and that one of the barriers to inclusion is the attitudes of the teachers (Fuchs, 2010; Landrum et al., 2004; Ross-Hill, 2007). Despite this information, in Illinois, $47.8 \%$ of students with ED spend less than $40 \%$ of their day in a regular education classroom. By taking a closer look at the perspectives of teachers on the inclusion of students with ED, I hoped to better understand the concerns that exist, the perspectives on the barriers that exist, and the supports that are needed. In my research, I used a qualitative, phenomenological approach. I completed five semistructured interviews. This chapter presents a discussion of the findings of this study. I compare the emergent themes to the information that was reviewed from the literature, discuss limitations with the study, make recommendations for policies and practice, discuss implications for further study, and make concluding remarks. 


\section{Emergent Themes and Research}

\section{Perspectives}

There were areas where my research was in agreement with the research I have reviewed, and other times when it was not. Rachel, Beth, Amanda, and Rebecca all had something positive to say about inclusion of students with ED. For example, Rachel said that having students with ED in your classroom "makes you a stronger teacher" and Rebecca spoke to the positives of social modeling for the students with ED. That being said, Rachel, Rebecca, Amanda, and Michelle had negative perspectives towards the inclusion of students with ED as well. Rebecca and Rachel expressed concerns over safety. Amanda had frustrations about the extra work and Michelle had concerns about lack of support . My qualitative research aligned with the findings of Ross-Hill's (2007) study that found mixed attitudes among general education teachers.

Rachel stated that, when you include students with disabilities at a young age, it is better for their self-esteem and the other students will accept them. This is in agreement with an administrator in Andreasen's (2014a) study, which felt that being included within the regular education environment would help students with disabilities to feel accepted.

Andreasen (2014a) also reported that some administrators believed that inclusion was beneficial, but not for every child. I found that this sentiment is true amongst teachers, too, when I interviewed Amanda and Rebecca, who felt that inclusion was only beneficial for some children. Rachel discussed the need for teams to consider safety of other students when considering placement.

Unlike Reasons's (2005) study and Heflin's and Bullock's (1999) study, my participants did not report feelings of skepticism, loss, or fear. They did, however, agree 
with teachers in Reasons's (2005) study who expressed concerns over being able to properly educate all of their students given the time demands of including a student with emotional disturbances. Amanda elaborated on this when she talked about the fact that general education teachers had an increasingly time consuming responsibility list.

\section{Barriers}

The four themes that my participants identified as barriers to the inclusion of students with ED were (a) safety, (b) student behaviors, (c) time, and (d) information. Some of these themes were mirrored in the literature. Amanda and Rebecca discuss the safety for other kids and safety for the student with ED being a barrier to successful inclusion. Amanda stated, "I get nervous when the behaviors become explosive and they can cause harm to themselves or another student." Though much of the literature reviewed in my study did not discuss safety as a barrier to inclusion, the fact that Reasons's (2005) and Heflin's and Bullock's (1999) participants felt fear might be contributed to safety concerns. .

Four of my five participants discussed the struggle there is with student behavior. Beth discussed student defiance being a hurdle to overcome. Rebecca talks about how the behavior of one student with ED can impact the whole class. The barrier of student behavior was discussed briefly in literature when Heflin and Bullock (1999) discuss behavior management as being a barrier.

Though the general education teachers in Reasons's (2005) study said they were overwhelmed and confused when faced with greater needs of students with disabilities, my participants indicated that they were concerned about the time needed to meet these needs. The participants in Fuchs's (2010) study and two of my participants, Beth and 
Rachel, discuss the burden of time for planning and implementation of inclusion. Amanda, Beth, Rachel, and Rebecca discuss how the time to deal with behavioral issues is a barrier. Reasons's (2005) participants felt that students with behaviors required more time and attention.

I found two areas of interest that my participants and the literature that I reviewed did not align. Michelle and Amanda both reference lack of information about the student as being a barrier to the inclusion of students with ED. According to Amanda, this lack of information is due to a lack in communication between parents, when she states “...parents need to disclose more information with teachers regarding medical diagnosis..." This barrier of information is not mentioned in the literature that I reviewed. On the other hand, the literature produced by Fuchs (2010) and Heflin and Bullock (1999) discusses the collaboration between the special education and general education teacher as being a barrier to inclusion. Though four of my five participants have experienced co-teaching with a special education teacher, none of the participants mentioned a barrier linked to that collaboration. In fact, only one of the participants, Rachel, even mentioned the possibility of a co-teacher for supports for inclusion.

\section{Supports}

In interviewing and reviewing the information provided by my five participants, I was able to identify three main themes in the areas of support: (a) planning for crisis, (b) professional development and training, and (c) staff. Where Amanda and Rebecca mentioned the need for behavior plans and plans for crisis to successfully implement inclusion, the research in my literature review did not mention planning. The research did, however, concur with my participants in the need for professional development and 
training. For Horrocks et al. (2008), principals felt there was a need for staff development for inclusion to succeed. Hu and Roberts (2011) called for more training. Rebecca stated, "We need more professional development on classroom management and handling the certain situations that may arise." A ccording to my participants and the research, training could also occur as part of professional development programs within a school district (Andreasen, 2014a; Andreasen, 2014b; Orr, 2009; Reasons, 2005; RossHill, 2007). This training should cover information such as "the characteristics of children with special needs, the individual education program, special education law, strategies for adapting instruction, collaboration, behavior management, conflict resolution, anger management, and discipline” (Reasons, 2005, pp. 54-55). Amanda, Rebecca, and the reviewed research speak to the fact that professional development is an important way to reach teachers who are working on including students with ED.

My research participants also spoke to the need for staff members that could support them in the inclusion of students with ED. These staff members include supportive principals, social workers, paraprofessionals, co-teachers, and behavioral specialists. Though Fuchs (2010) and Orr (2009) reported administrative support having a large impact on inclusion within a school and other research spoke to the collaboration between the general education and special education teachers, none of the research reviewed mentioned social workers, paraprofessionals, and behavioral specialists (Heflin \& Bullock, 1999; Hoffman, 2006; Orr, 2009).

\section{Limitations of the Study}

All research studies are subject to limitations. It is up to the researcher to acknowledge and discuss these limitations. The limitations that are present in my 
research study include: (a) personal bias, (b) generalizability, (c) interview process, (d) personal connections, and (e) researcher bias.

\section{Personal Bias}

In studies that involve interviews, there is a potential distortion of research due to the fact that people do and say different things in different situations due to personal bias (Taylor, Bogdan, \& DeVault, 2016). Participants may believe that students with ED either should or should not be included in a general education classroom. With these beliefs, they may be swayed to report data that would support their belief. Participants may also alter information regarding their perspectives of the inclusion of students with ED to match the perceived beliefs within the district about inclusion. Though this is a potential limitation of interview studies, from a social constructivist perspective, getting through that bias and seeing how it affects the participants' viewpoints is part of the purpose of research. This means that researchers can learn a lot about interview participants by what they say. To help minimize this bias, participants were given an atmosphere that would most likely encourage them to talk freely. In order to encourage this, I emphasized confidentiality and offered a time and location for the interview of the participant's choosing.

\section{Generalizability}

This study examined the perspectives of a small number of participants from a volunteer population in one school district in Central Illinois. This means that the sample of the population that is reported on will be small, which limits the generalizability of the study to teachers in other locations or in a wider population. It should be noted, however, that qualitative, phenomenological results usually cannot be generalized. This is because 
answers are based on personal experiences and personal bias influences these. T hough generalizability is a limitation due to the small sample size, this research study does give me insight into the perceptions of teachers who have taught students with ED.

\section{Interview Process}

A potential limitation for this research study is that I was new to completing qualitative interviews. If my interviewing skills better developed, I may have been able to draw more information from the participants. During the interviews themselves, I did not ask as many probing questions as I could have because at the time I did not realize they would collect more information. As a result, the interviews ranged in length of time from 22 minutes to 45 minutes. Despite this, I believe that the participants were very forthcoming, and gave me as much information as they were able to under the circumstances.

\section{Personal Connections}

Another limitation is the use of general education, elementary teachers within the urban school district. Due to the researcher's profession as a behavioral consultant within the school district, there is the potential that the participant may be a teacher that the researcher has worked with in the past, present, or future. Participants who have interacted with behavioral consultants within the school district in the past or present are aware of the availability of the behavioral consultants services. Some of the participants may have had a paraprofessional for behavioral needs within their classroom at some point in the past or present. As a result, their perspective of the effectiveness and availability of these services may have led to the request for more staff members. 


\section{Researcher Bias}

The study is also limited by the potential for researcher bias. This manifests itself in factors such as the literature reviewed, selection of the research design and procedure, selection of the sample population for the study, and the interpretation of the findings of the study. In order to minimize researcher bias, I have used low-inference descriptors. This means that information from the interview transcriptions were used to support conclusions that are drawn. This limitation was also addressed by including a statement of position to make readers aware of my personal background and beliefs.

The limitations that are present in this research study are limitations that are commonly found in phenomenological qualitative approaches. The phenomenological studies include interviewing the people who have experienced the phenomenon and look to understand that phenomenon through their viewpoints (McPhail, 1995). The human consciousness that is examined in phenomenological research is affected by past experiences and beliefs (McPhail, 1995). The purpose behind phenomenological research is to understand that consciousness.

\section{Recommendations for Policies and Practice}

Michelle perhaps put it best, when she was asked if she had further information to share. She stated,

And, with talking to people and hearing teachers talk about the problems that we're having, the time constraints that I have, that I'm not fully informed...nor do I feel adequately ready or prepared to deal with it. That something will be done. 
It is the duty of school districts to provide students with a free and appropriate education in the least restrictive environment possible. Based on the literature that was reviewed and my research, there are several different areas that can be developed to make the inclusion of students with ED more successful.

\section{Barriers}

Perspectives. The research that has been completed calls for further investigation and identification of the barriers and supports to inclusion, particularly that of teacher attitudes (Fuchs, 2010; MacFarlane \& Woolfson, 2013; Orr, 2009; Ross-Hill, 2007). According to Ross-Hill (2007), there is a direct relationship between the teachers' attitudes and the success of the student within the inclusive classroom. The promising finding of my research study is that there are positive perspectives towards the inclusion of students with ED. The negative perspectives that were expressed by the teachers in my research study concerned safety, time, and support. All of these issues are ones that can be addressed, as I will discuss in the area of supports. Research suggests that, to address the area of teacher perspectives, districts should develop pro-inclusion philosophies and that they should be supported at all levels (Orr, 2009).

Information sharing. Though the area of sharing information about the student's disability with teachers and students is not discussed in the literature, two of my participants expressed that this was a barrier. This is a barrier that needs to be addressed during the planning phase for the inclusion of a student with ED. Communication needs to occur between the general education teacher, the social worker, the special education teacher, and the parent regarding important information about the student such as 
medication, medical diagnosis, and information in their Individualized Education Program (IEP).

Another concern brought up by Michelle in the area of information regarded the information that is shared with other students. Michelle gave a solution to this within her interview as well. She stated

I think that if we, as educators or as a school system, if we address head on problems like that, I think it would help the kids in the classroom deal with it better.

In Michelle's case, the social worker came in and did a lesson that addressed how to handle when someone in the classroom had sexually inappropriate behavior. I have been in classrooms before where the classroom teacher included lessons that addressed disability awareness to help students understand others within their building. This process helps generate a culture of understanding disabilities rather than a culture of fear of the unknown. Preparing for lessons on disability awareness should be a part of the planning process for inclusion.

\section{Supports}

Planning for crisis. Planning is an area that can help address the issues of safety, student behaviors, and information that some of the teachers expressed were barriers for including students with ED. Though the literature reviewed did not express the need for planning, two of my participants discussed this. We can start even before the students with ED set their feet into the classroom by forming a supportive team and having a plan of action for the inclusion of the student. This team should include the principal, the social worker, the teacher, any further support staff, community agencies the student is 
involved with, the family of the student, and the student. This team should consist of the same individuals that are a part of the student's IEP team. The plan should include information as far as what steps will be taken in the event of a crisis and the strategies should be included as a part of the behavior plan in the student's IEP.

Professional development. Another area that can be developed is that of professional development. Amanda, Rebecca, and much of the research call for professional development and training to be a part of the inclusion of students with disabilities (Andreasen, 2014a; Andreasen, 2014b; Horrocks et al., 2008; Hu \& Roberts, 2011; Orr, 2009; Reasons, 2005; Ross-Hill, 2007). Research and my interviews support that professional development needs to be created for teachers focusing on students with ED, strategies for working with students with behavioral problems, collaboration, and classroom management (Reasons, 2005). This training should include any staff who may interact with students with ED within the building. Teachers who are working with students with ED should be provided the opportunity to have ongoing coaching in regards to behavior management strategies within their classrooms.

Staff. Administrative support has a large impact on inclusion within a school (Fuchs, 2010; Orr, 2009). Both Beth and Rebecca expressed the supportive principal as part of what they felt was needed for the inclusion of students with ED. Though the literature reviewed does not cover additional staff that would be beneficial for assisting with the inclusion of students with ED, my interviews supported access to a full-time social worker, a paraprofessional, and a behavioral coach or consultant. Though in a ideal setting, the requests by my participants would be more beneficial, reality is that budgets constrain us. I believe that each building should have a supportive principal, and 
a full-time social worker. The need for a co-teacher and a paraprofessional should be evaluated on a case-by-case basis. Behavioral coaches or consultants should also be available for consultation with the teacher. Districts will need to determine what ratio would be appropriate so that the behavioral coaches will be able to provide some of the hands-on training and professional development for the teachers. Districts will also need to establish policies for how involved behavioral consultants will be while working with the students.

\section{Implications for Further Study}

Inclusion is present in many school districts and has taken many forms. The present study explored the perspectives of general educators towards the inclusion of students with ED. I recommend the following paths for further research:

1. With respect to the differences between past research by Reasons (2005) and Heflin and Bullock (1999) and my research, the question arises of why are there discrepancies between my findings and past research? Further research needs to be completed to see if the findings of my study are consistent in other districts across the nation and in districts of differing demographics. Are the differences in general education teacher perspectives due to time that has elapsed between the studies and policies that have been implemented during that time? To verify the generalization of my findings, these research studies should also be completed using interviews for a phenomenological study.

2. Additional research needs to be completed on the breakdown in communication and information that the general education teachers in my study felt existed. Does 
this breakdown exist for other teachers? Where is the breakdown occurring and how can we bridge that gap?

3. Future research could explore the utilization of support staff within the buildings. This should include information on paraprofessional use in classrooms that are including students with ED. For the districts that employ behavioral specialists, coaches, or consultants, how do different districts utilize them? How do their job positions vary?

4. Prior to creating the professional development for different school districts, research needs to be completed within that school district to determine what strategies general education teachers know how to use in regards to working with the students with ED. Which of these strategies can be universally implemented? Which strategies benefit students without ED as well?

5. There needs to be further qualitative and quantitative research into other stakeholders perspectives on the inclusion of students with ED. Different perspectives that have yet to be looked at include the parents and guardians of the students with ED, the students with ED, and the students without ED within the classroom.

\section{Concluding Remarks}

Students with ED deserve education in the least restrictive environment possible, but existing research suggests that this is not the case. Landrum et al., (2004) found a negative correlation between graduation with a diploma and placement in a restrictive setting for students with ED. Despite the results from studies such as Landrum et al. (2004), almost half of students with ED within Illinois are being serviced with less than 
$40 \%$ of their day in a general education classroom. This is very discouraging, however, based on results of my study, there is reason to be optimistic. What is encouraging is the fact that general education teachers were willing to open up and discuss what their views on the inclusion of students with ED were. They were able to express what barriers were and what supports were needed. The participants in my interview expressed a willingness to work with the inclusion of students with ED. Currently, we are limited by larger influences such as policy, how well policies are implemented, and how resources are distributed. Change needs to occur to help overcome the barriers and provide the identified supports to encourage the inclusion of students with ED. This change needs to happen on many levels: (a) federal, (b) state, and (c) local. In Rebecca's words, "They [the students with ED] still deserve their education. They still deserve the best education that they can possibly have." 


\section{REFERENCES}

Andreasen, F. E. (2014a). Supporting inclusion: School administrators' perspectives and practices. Lanham, Maryland: Rowman \& Littlefield.

Andreasen, F. E. (2014b). Inclusion: Teachers' perspectives and practices. Lanham, Maryland: Rowman \& Littlefield.

Andrews, T. (2012). What is social constructionism? Gounded Theory Review: An International Journal, 11(1). Retrieved from http://groundedtheoryreview.com/2012/06/01/what-is-social-constructionism/

Blankenship, T., Boon, R. T., \& Fore, C. (2007). Inclusion and placement decisions for students with special needs: A historical analysis of relevant statutory and case law. Electronic Journal for Inclusive Education, 2(1), 1-10. Retrieved from http://corescholar.libraries.wright.edu/cgi/viewcontent.cgi?article=1074\&context $=$ ejie

Clough, P., \& Nutbrown, C. (2002). Student's guide to methodology. London, England: SAGE Publications.

Creswell, J. W. (2013). Qualitative inquiry \& research design: Choosing among five approaches. Thousand Oaks, California: SAGE Publications.

Denzin, N. K., \& Lincoln, Y. S. (Eds.) (2005). The sage handbook of qualitative research. London, England: SAGE Publications.

Dessemontet, R. S. \& Bless, G. (2013). The impact of including children with intellectual disability in general education classrooms on the academic achievement of their 
low-, average-, and high-achieving peers. Journal of Intellectual \& Developmental Disability, 38(1), 23 - 30.

Drysdale, M.T.B., Williams, A., Meaney, G. J. (2007). Teachers' perceptions of integrating students with behaviour disorders: Challenges and strategies. Exceptionality Education Canada, 17(3), 35-60.

Dudley-Marling, C. \& Burns, M. B. (2014). Two perspectives on inclusion in the United States. Global Education Review, 1(1), 14-31.

Fuchs, W. W. (2010). Examining teachers' perceived barriers associated with inclusion. SRATE Journal, 19(1), 30-35. Retrieved from http://www.eric.ed.gov/contentdelivery/servlet/ERICServlet?accno=EJ948685

Heflin, L.J. \& Bullock, L.M. (1999). Inclusion of students with emotional/behavioral disorders: A survey of teachers in general and special education. Preventing School Failure, 43(3), 103-111.

Hoffman, K. J. (2006). Inclusion: Secondary teacher attitudes toward inclusion of special needs students into regular classrooms (Doctoral dissertation). Available from ProQuest Dissertations and Theses database. (UMI No. 3250133).

Holliday, A. (2000). Doing and writing qualitative research. London, England: SAGE Publications.

Horrocks, J. L., White, G., \& Roberts, L. (2008). Principals’ Attitudes Regarding Inclusion of Children with Autism in Pennsylvania Public Schools. Journal of Autism and Developmental Disorders, 38, 1462-1473. 
Hu, B. Y. \& Roberts, S. K. (2011), When inclusion is innovation: An examination of administrator perspectives on inclusion in China. Journal of School Leadership, $21,548-581$.

Jones, P., Fauske, J., \& Carr, J. (2011). Leading for inclusion: How schools can build on the strengths of all learners. London, England: Teachers College Press.

Kalambouka, A., Farrell, P., Dyson, A., \& Kaplan, I. (2007). The impact of placing pupils with special educational needs in mainstream schools on the achievement of their peers. Educational Research, 49(4), 365-382. doi:

$10.1080 / 00131880701717222$

Khudorenko, E. A. (2011). Problems of the education and inclusion of people with disabilities. Russian Education and Society,53(12), 82-91.

Landrum, T., Katsiyannis, A., \& Archwamety, T. (2004). An analysis of placement and exit patterns of students with emotional or behavioral disorders. Behavioral Disorders, 29(2), 140-153.

MacFarlane, K., \& Woolfson, L. (2013). Teacher attitudes and behavior toward the inclusion of children with social, emotional, and behavioral difficulties in mainstream schools: An application of the theory of planned behavior. Teaching and Teacher Education, 29, 46-52. doi:10.1016/j.tate.2012.08.006

McPhail, J.C. (1995). Phenomenology as philosophy and method: Applications to ways of doing special education. Remedial and Special Education, 16(3), 159-165.

Mills v. Board of Education, 348 F. Supp. 866 (1972). 
Mowat, J. (2009). The inclusion of pupils perceived as having social and emotional behavioural difficulties in mainstream schools: A focus upon learning. Support for Learning, 24(4), 149-169. doi:10.1111/j.1467-9604.2009.01419.x

Nelson, K. A. (2000). Inclusion: A content analysis of general and special education teachers' and administrators' perspectives. (Doctoral dissertation). Available from ProQuest Dissertations and Thesis database. (UMI No. 999099)

Obiakor, F. E., Harris, M., Mutua, K., Rotatori, A., \& Algozzine, B. (2012). Making inclusion work in general education classrooms. Education and Treatment of Children, 35(3), 477-490.

Orr, A.C. (2009). New special educators reflect about inclusion: Preparation and K-12 current practice. Journal of Ethnographic \& Qualitative Research, 3(4), 228-239.

Osgood, R. L. (2005). The history of inclusion in the United States. Washington, D.C.: Gallaudet University Press.

Peetsma, T., Vergeer, M., Roeleveld, J., \& Karsten, S. (2001). Inclusion in education: Comparing pupils' development in special and regular education. Educational Review, 53(2), 125-135.

Reasons, R.L. (2005). General educators' attitudes and perceptions towards students with a social and emotional disturbance (SED) included within their regular education classrooms: Implications for leaders. (Doctoral dissertation). Available from ProQuest Dissertations and Theses database. (UMI No. 3170264).

Ross-Hill, R. (2007). Regular education teacher attitudes on the inclusion of students with special needs in elementary and secondary school classrooms. (Doctoral 
dissertation). Available from ProQuest Dissertations and Theses database. (UMI No. 3277886)

Scruggs, T.E., Mastropieri, M. A., McDuffie, K. A. (2007). Co-teaching in inclusive classrooms: A metasynthesis of qualitative research. Exceptional Children, 73(4), $392-416$.

Special Olympics (2015). History of Special Olympics. Retrieved from: http://www.specialolympics.org/history.aspx

Taylor, S. J., Bogdan, R., DeVault, M. (2016). Introduction to qualitative research methods. Hoboken, New Jersey: John Wiley \& Sons, Inc.

Tsokova, D. \& Tarr, J. (2012). Diverse perspectives on inclusive school communities. London, England: Routledge.

U.S. Department of Education (1995). $17^{\text {th }}$ Annual report to Congress on the implementation of the Individual with Disabilities Education Act. Washington, DC. Retrieved from http://www2.ed.gov/pubs/OSEP95AnlRpt/index.html

U.S. Department of Education. (2014). 36 ${ }^{\text {th }}$ Annual report to Congress on the implementation of the Individual with Disabilities Education Act. Washington, DC. Retrieved from http://www2.ed.gov/about/reports/annual/osep/2014/parts-bc/36th-idea-arc.pdf 
APPENDIX A

RECRUITMENT FLYER

General Education, Elementary School Teachers Needed for Research Study

Who?

General Education, Elementary School Teachers Who Have Experience with the

Inclusion of Students with Emotional Disturbances

Why?

To Discuss Perceptions on the Inclusion of Students with Emotional Disturbances in

the General Education Classroom

To Do What?

To participate in 1 interview lasting 45 - 90 minutes

If interested, contact Leona O'Dear at xxxxxxx@xxxxx.xxx or

(xxx)xxx-xxxx by December $11^{\text {th }}$.

Participation in this study is voluntary and you may withdraw from the study at any time with no penalty or loss of privileges. Your name and identifying information will not be mentioned in the study. Every measure possible will be taken in order to honor and protect your confidentiality. The purpose of this study is to study general education, elementary school teachers' perspectives towards the inclusion of students with Emotional Disturbances, including barriers and supports that exist or are needed. All information will be kept confidential. All participants will receive a Starbuck's gift card regardless of whether or not they finish the interview.

Research at Illinois State University that involves human participants is carried out under the oversight of the Institutional Review Board. Questions or problems regarding the activities should be addressed to Research Ethics and Compliance Office, Campus Box 3330, Normal, IL 61790-3040, or phone (309)438-2529. 


\section{APPENDIX B}

\section{SEMI-STRUCTURED INTERVIEW PROTOCOL}

Project: General Education, Elementary School Teacher Perspectives on the Inclusion of Students with ED

Time of Interview: xx:xx a.m./p.m.

Date: $\mathrm{xx} / \mathrm{xx} / 2016$

Place: School xx - Jane Doe's classroom

Interviewer: Leona O’Dear

Interviewee: Jane Doe

Position of interviewee: General Education Teacher

My name is Leona O'Dear, and I am currently working on completing my research project under the direction of my thesis chair, Dr. Mark Zablocki. The Special Education Master's Program at Illinois State University requires the project to complete the degree. I have chosen to research the perceptions of general education, elementary school teachers towards the inclusion of students with emotional disturbances (ED) within the general education classroom. Your participation in this study would include one interview. It would take about 45-90 minutes. During the interview, I would like to ask you questions about your teaching experience and experiences with the inclusion of students with ED.

I would like to audio tape these interviews so that I can create verbatim transcripts to use in the data analysis. The tape recordings will be erased after we have completed the study or no later than December of 2017. The audiotapes will be stored in my office. After the interviews are transcribed, you will have the opportunity to review the transcript. Only Dr. Mark Zablocki and myself will have access to the tapes. Your name and identifying information about you will not be used in the verbatim. All individuals, school names, and so on will be given pseudonyms so that individuals and organization remain confidential.

[Turn on the tape recorder and test it.]

Questions: 
1. What is your teaching experience?

a. Probe: What grade levels have you taught?

b. Probe: How long have you been teaching for?

c. Probe: Have you ever co-taught with a special education teacher?

d. Probe: Tell me more.

2. What are your views about inclusion?

a. Probe: I need more detail.

b. Probe: Tell me more.

3. What experiences have you had with inclusion in your classroom?

a. Probe: What disabilities have students within your classroom had?

b. Probe: What does "not much" mean?

c. Probe: Tell me more.

4. What barriers have you experienced with inclusion?

a. Probe: Were you able to overcome these barriers? How?

b. Probe: Tell me more.

5. What experiences have you had with the inclusion of students with emotional disturbances within your classroom?

a. Probe: What did you view as successful about the inclusion of these students?

b. Probe: What did you view as a challenge for the inclusion of these students?

c. Probe: Tell me more.

6. What are your views on the inclusion of students with emotional disturbances?

a. Probe: Tell me more.

b. Probe: I need more detail.

7. What barriers do you feel would be experienced during the inclusion of students with emotional disturbances?

a. Probe: Are these barriers for the student with the emotional disturbances, for the other students, or for the staff members involved?

b. Probe: Tell me more.

8. What supports would you like to see provided?

a. Probe: Where would you like these supports provided?

b. Probe: Who could provide these supports?

c. Probe: Tell me more.

9. What further information would you like to share on this topic?

a. Probe: Tell me more.

[Thank the individuals for their cooperation and participation in this interview. Assure them the confidentiality of the responses.] 